NBER WORKING PAPER SERIES

DYNAMIC BANKING AND THE VALUE OF DEPOSITS

\author{
Patrick Bolton \\ Neng Wang \\ Jinqiang Yang \\ Working Paper 26802 \\ http://www.nber.org/papers/w26802 \\ NATIONAL BUREAU OF ECONOMIC RESEARCH \\ 1050 Massachusetts Avenue \\ Cambridge, MA 02138 \\ February 2020, Revised April 2023
}

Previously circulated as "Leverage Dynamics and Financial Flexibility." We thank the anonymous Associate Editor, two anonymous referees, Jason Allen, Adrien d'Avernas, Juliane Begenau (discussant), Philip Bond, Markus Brunnermeier, Peter DeMarzo, Jason Donaldson, Itamar Drechsler (discussant), Philip Dybvig, Isil Erel, Xavier Gabaix, Zhiguo He (discussant), Ji Huang (discussant), Sebastian Infante, Bart Lambrecht, Anil Kashyap, Naveen Khanna, Arvind Krishnamurthy, Bernadette Minton, Cyril Monnet (discussant), Stefan Nagel, Dirk Niepelt (discussant), Christian Opp (discussant), Guillermo Ordoñez, Jonathan Payne (discussant), Monika Piazzesi, Alexi Savov (discussant), Dejanir Silva (discussant), René Stulz, Anjan Thakor, Quentin Vandeweyer, Matías Vieyra (discussant), Ernst-Ludwig von Thadden, Larry Wall (discussant), Mike Weisbach, Chao Ying (discussant), Haoxiang Zhu and seminar/conference participants at Biennial International Association of Deposit Insurers Conference, BI-SSE Asset Pricing \& Financial Econometrics Conference, Cambridge Corporate Finance Theory Symposium, CESifo Macro Money \& International Finance, China International Conference in Finance, China International Conference in Macroeconomics, European Finance Association 2021, Federal Reserve Board, FOM Virtual Corporate Finance Fridays, Fed-Maryland ShortTerm Funding Markets 2021, Midwest Finance Association 2021, NBER Summer Institute 2021, Northern Finance Association 2021, Society for Economic Dynamics 2021, Ohio State University, and Washington University in St. Louis Annual Corporate Finance Conference. The views expressed herein are those of the authors and do not necessarily reflect the views of the National Bureau of Economic Research.

NBER working papers are circulated for discussion and comment purposes. They have not been peer-reviewed or been subject to the review by the NBER Board of Directors that accompanies official NBER publications.

(C) 2020 by Patrick Bolton, Neng Wang, and Jinqiang Yang. All rights reserved. Short sections of text, not to exceed two paragraphs, may be quoted without explicit permission provided that full credit, including $\odot$ notice, is given to the source. 
Dynamic Banking and the Value of Deposits

Patrick Bolton, Neng Wang, and Jinqiang Yang

NBER Working Paper No. 26802

February 2020, Revised April 2023

JEL No. G11,G31,G32,G35

\section{ABSTRACT}

We propose a theory of banking in which banks cannot perfectly control deposit flows. Facing uninsurable loan and deposit shocks, banks dynamically manage lending, wholesale funding, deposits, and equity. Deposits create value by lowering funding costs. However, when the bank is undercapitalized and at risk of breaching leverage requirements, the marginal value of deposits can turn negative as deposit inflows, by raising leverage, increase the likelihood of costly equity issuance. Banks' inability to fully control leverage distinguishes them from non-depository intermediaries. Our model suggests a re-evaluation of leverage regulations and offers new perspectives on banking in a low interest-rate environment.

Patrick Bolton

Columbia Business School

804 Uris Hall

New York, NY 10027

and NBER

pb2208@columbia.edu

Neng Wang

Columbia Business School

3022 Broadway, Uris Hall 812

New York, NY 10027

and NBER

nw2128@columbia.edu
Jinqiang Yang

Shanghai University of Finance

and Economics

Guoding Rd. 777

Shanghai, 200433

China

yang.jinqiang@mail.sufe.edu.cn 


\title{
Dynamic Banking and the Value of Deposits*
}

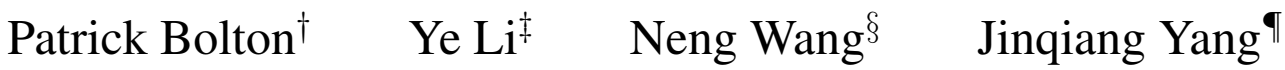

First Draft: June 10, 2020 | Current Version: April 7, 2023

\begin{abstract}
We propose a theory of banking in which banks cannot perfectly control deposit flows. Facing uninsurable loan and deposit shocks, banks dynamically manage lending, wholesale funding, deposits, and equity. Deposits create value by lowering funding costs. However, when the bank is undercapitalized and at risk of breaching leverage requirements, the marginal value of deposits can turn negative as deposit inflows, by raising leverage, increase the likelihood of costly equity issuance. Banks' inability to fully control leverage distinguishes them from non-depository intermediaries. Our model suggests a re-evaluation of leverage regulations and offers new perspectives on banking in a low interest-rate environment.
\end{abstract}

${ }^{*}$ We thank the anonymous Associate Editor, two anonymous referees, Jason Allen, Adrien d'Avernas, Juliane Begenau (discussant), Philip Bond, Markus Brunnermeier, Peter DeMarzo, Jason Donaldson, Itamar Drechsler (discussant), Philip Dybvig, Isil Erel, Xavier Gabaix, Zhiguo He (discussant), Ji Huang (discussant), Sebastian Infante, Bart Lambrecht, Anil Kashyap, Naveen Khanna, Arvind Krishnamurthy, Bernadette Minton, Cyril Monnet (discussant), Stefan Nagel, Dirk Niepelt (discussant), Christian Opp (discussant), Guillermo Ordoñez, Jonathan Payne (discussant), Monika Piazzesi, Alexi Savov (discussant), Dejanir Silva (discussant), René Stulz, Anjan Thakor, Quentin Vandeweyer, Matías Vieyra (discussant), Ernst-Ludwig von Thadden, Larry Wall (discussant), Mike Weisbach, Chao Ying (discussant), Haoxiang Zhu and seminar/conference participants at Biennial International Association of Deposit Insurers Conference, BI-SSE Asset Pricing \& Financial Econometrics Conference, Cambridge Corporate Finance Theory Symposium, CESifo Macro Money \& International Finance, China International Conference in Finance, China International Conference in Macroeconomics, European Finance Association 2021, Federal Reserve Board, FOM Virtual Corporate Finance Fridays, Fed-Maryland Short-Term Funding Markets 2021, Midwest Finance Association 2021, NBER Summer Institute 2021, Northern Finance Association 2021, Society for Economic Dynamics 2021, Ohio State University, and Washington University in St. Louis Annual Corporate Finance Conference.

${ }^{\dagger}$ Columbia University, Imperial College, CEPR, and NBER. E-mail: pb2208@columbia.edu

$\ddagger$ University of Washington, Foster School of Business. E-mail: liye@uw.edu

$\S$ Columbia Business School and NBER. E-mail: neng.wang@columbia.edu

TShanghai University of Finance and Economics. E-mail: yang.jinqiang@mail.sufe.edu.cn 


\section{Introduction}

We propose a new dynamic banking model with both asset return risk and deposit funding risk. The main novelty is in the way we model deposit liabilities and in the role of leverage regulations such as the supplementary leverage ratio (SLR) in affecting the bank's dynamic balance-sheet management. Demand deposit contracts allow depositors to freely put money in and take money out of their deposit accounts. This is necessary for the seamless operation of the payment system. The consequence, however, is that banks cannot perfectly control their deposits.

In our model deposit inflows create both opportunities and challenges for banks. Deposits are a source of cheap funding. Depositors accept relatively low interest rates for the convenience of using deposits as a means of payment. ${ }^{1}$ However, whether deposit inflows are good or bad for the bank depends on the bank's balance-sheet condition. The key variable reflecting the state of the bank's balance sheet in our model at time $t$ is the ratio of its equity capital $K_{t}$ and deposits $X_{t}$, denoted by $k_{t} \equiv K_{t} / X_{t}$. When the bank is well capitalized (in that $k_{t}$ is high), additional deposits are a source of cheap financing allowing the bank to expand profitable lending. But when $k_{t}$ is low, additional deposit inflows may force the bank into a costly equity issuance so as to comply with leverage regulations. Facing equity issuance costs (Myers and Majluf, 1984), the bank finds it costly to accommodate deposit inflows when $k_{t}$ is low.

A key result of our analysis is that the bank's marginal value of deposits (the deposit marginal q) may turn negative when it has a low $k_{t}$ and is close to breaching leverage regulations. At the onset of the COVID-19 pandemic, U.S. banks have undergone unprecedented balance-sheet expansions because of massive deposit inflows. From Q4 2019 to Q1 2020, JP Morgan Chase had an increase of $18 \%$ of its deposit base, and the deposit liabilities of Citigroup and Bank of America increased by $11 \%$ and $10 \%$, respectively. ${ }^{2}$ Contrary to received wisdom, this significant increase in deposit funding did not increase bank valuations nor did it stimulate lending. US regulators traded off the financial stability benefits of leverage regulations against the costs for banks facing large

\footnotetext{
${ }^{1}$ A recent literature incorporates the money premium into macroeconomic and banking models (Stein, 2012; DeAngelo and Stulz, 2015; Krishnamurthy and Vissing-Jørgensen, 2015; Nagel, 2016; Begenau, 2020)

${ }^{2}$ See "U.S. Banks are 'Swimming in Money' as deposits increase by 2 trillion dollars amid the coronavirus" by Hugh Son, CNBC June 21, 2020. Such deposit influx also happened in the financial crisis of 2007-2008.
} 
deposit inflows and decided to relax the SLR. ${ }^{3}$ In April 2021, the SLR was restored as regulators faced a different trade-off. In response, banks encouraged depositors to move money to money market funds that in turn invest in the reverse repo facility at the Federal Reserve. ${ }^{4}$ Within three months, the reverse repo amount rose from almost zero to one trillion dollars. ${ }^{5}$

The key to our mechanism is the link between deposit inflows and costly equity issuance. In our model, the equity issuance (lower) boundary for $k_{t}$ is given by the SLR but it can arise from other regulations. ${ }^{6}$ To be sure, our results hold as long as bank leverage is bounded above. The banking literature has modeled deposit risk mostly in terms of the risk of depositors running and forcing the bank into fire-sale liquidations of its assets (Diamond and Dybvig, 1983). Our model departs from this framing by introducing a risk with respect to deposit inflows under equity issuance costs. Thus, in our model both inflow and outflow shocks can be problematic.

The bank's inability to fully control the size of its liabilities gives rise to a balance-sheet management problem that is conceptually very different from that of non-depository intermediaries and nonfinancial firms. The deposit stock in our model follows a stochastic process partially controlled by the bank through the deposit rate, $i_{t}$. The optimal deposit rate policy resembles the q-theory of investment (Lucas and Prescott, 1971; Hayashi, 1982). The difference is that unlike in the q-theory literature, where the firm invests in productive capital, in our model the bank sets $i_{t}$ to attract (or repel) deposits as a function of the marginal value of deposits (the deposit marginal $q$ ). The deposit base in our model is sticky and has random yet persistent flows. Raising the deposit rate $i_{t}$ is akin to investing in customer capital (the deposit base) to lower the bank's financing costs.

\footnotetext{
${ }^{3}$ See "Fed's Powell makes case why Congress should relax bank capital rule" by Hannah Lang, American Banker July 29, 2020. The SLR was likely binding as it affected the Treasury market (He, Nagel, and Song, 2021).

${ }^{4}$ See "Cash-rich US banks move to reduce corporate deposits" by Imani Moise, Financial Times May 3, 2021. See also, "Banks to Companies: No More Deposits, Please" by Nina Trentmann, Wall Street Journal June 9, 2021.

${ }^{5}$ A similar episode took place following the collapse of SVB in March 2023 when deposits rushed into larger banks. As William Dudley, the former President of the Federal Reserve Bank of New York commented, the SLR again caused a sharp rise in reverse repo. See, "Deposit Outflows Shine Light on Fed Program That Pays Money-Market Funds" by Eric Wallerstein and Nick Timiraos, Wall Street Journal April 7, 2023.

${ }^{6}$ The SLR represents the U.S. implementation of the Basel III Leverage Ratio. During the Covid-19 pandemic, European banks faced similar challenges of complying with their versions of leverage regulations in response to massive deposit inflows. See "Banks in Germany Tell Customers to Take Deposits Elsewhere" By Patricia Kowsmann, Wall Street Journal March 1, 2021. Beyond the SLR, US banks have long been subject to regulations on the ratio of Tier 1 capital to total consolidated assets ("U.S. leverage ratio"). The main difference between the SLR and U.S. leverage ratio is that the former accounts for both on- and certain off-balance sheet assets and exposures.
} 
When $k_{t}$ is low (and close to the equity issuance boundary), however, the bank wants to lower $i_{t}$ in an effort to forestall any unintended leverage expansion due to deposit inflow shocks. ${ }^{7}$

Another realistic feature of our model is a zero lower bound for the deposit rate. This lower bound has been binding in the low interest-rate environment following the global financial crisis (Heider, Saidi, and Schepens, 2019). A lower bound further limits the bank's ability to control deposit flows, strengthening our main mechanism. Once $i_{t}$ hits zero, the bank loses its ability to counteract deposit-inflow shocks through further reductions of the deposit rate. Our model thus sheds new light on the critical importance of the prevailing interest rate level $r$ for banks. As in Drechsler, Savov, and Schnabl (2017), the bank earns a deposit spread, $r-i_{t}$. When $k_{t}$ is high, the bank raises the deposit rate $i_{t}$ to attract more deposits and to gain some slack, so that if $k_{t}$ declines in the future the bank will have more room to reduce $i_{t}$ before hitting the deposit rate lower bound. To be sure, when $r$ is high, the bank has more flexibility in raising its deposit rate in the high- $k_{t}$ region without squeezing the deposit spread, $r-i_{t}$, too much. The distance between $\mathrm{r}$ and zero determines the degree of flexibility to control deposit flows through adjusting the deposit rate. In a low interest rate environment, the bank finds it more difficult to manage deposit-flow risk.

In an extension, we allow the bank to set a negative deposit rate. However, setting a negative deposit rate is such a salient move that it may induce depositors to withdraw in large numbers. ${ }^{8}$ Formally, when $i_{t}<0$, the bank faces the risk of a Poisson-arriving large withdrawal of deposits. The Poisson arrival rate decreases in $i_{t}$, so that the further below zero $i_{t}$ is, the more likely is a withdrawal event. In our baseline model, the deposit stock follows a diffusion process with Brownian shocks and continuous paths. Dealing with such small withdrawals does not incur costs. In this extension, to meet Poisson-arriving large withdrawals, the bank has to sell assets at a discount. Therefore, the bank burdened with unwanted deposits may want to set a negative deposit rate but is concerned with upsetting depositors and causing large withdrawals (and the asset liquidation costs). The extended model generates dynamics similar to that of our baseline model.

\footnotetext{
${ }^{7}$ Note that in our model, the regulatory constraints ensure that the bank never becomes insolvent. When bank solvency becomes a concern, especially during crises, undercapitalized and over levered banks may have to raise deposit rates to compensate depositors' exposure to default risk and to prevent runs (Acharya and Mora, 2015).

${ }^{8}$ Holding cash may incur costs (Rognlie, 2016), so depositors may tolerate a slightly negative rate. Changing the threshold from zero to a negative number, the model dynamics will not change significantly.
} 
In practice, the bank may take other measures to reduce deposits. In another extension, we let the bank to pay a cost to reduce its deposits by some lumpy amount. This cost captures efforts to get depositors to move money out of deposit accounts and into money market funds. It also captures the losses banks face on their deposit franchise once money is pushed out of deposit accounts. In contrast to deposits on which banks earn a deposit spread due to depositors' inertia in switching banks (Drechsler, Savov, and Schnabl, 2017), money market funds pay the market rate.

The way we model deposits allows us to sharply distinguish between deposits and wholesale funding (short-term debt). With short-term debt, the bank can always choose to stop borrowing at maturity, and therefore, does not face the problem of unwanted leverage. In contrast, deposits are in effect long-term contracts without a well-defined maturity. Deposits leave the bank only when depositors withdraw funds. We show that when $k_{t}$ is high, the bank issues short-term debt to obtain additional financing for lending. If $k_{t}$ declines, the bank deleverages by reducing its short-term debt. And when $k_{t}$ approaches the lower boundary of costly equity issuance, the bank switches from issuing short-term bonds to holding risk-free bonds, thereby de-risking the asset side of its balance sheet, given that the risk on the liability (deposit) side cannot be fully controlled.

By incorporating leverage risk from uncertain deposit flows, our model provides a new perspective on the bank's incentive to lend and take on credit risk on its loan book. During the Covid19 pandemic, many commentators and policy makers were puzzled why banks did not increase lending in response to deposit inflows. Our model provides an explanation of this phenomenon. When the bank is concerned about high leverage and potential costly equity issuance in the foreseeable future, deposit inflows further reduce $k_{t}$, dampening the bank's incentive to lend. Indeed, the prospect of loan losses would reduce equity capital and further raise the leverage ratio. Our optimal lending policy is characterized by a formula akin to the portfolio choice of Merton (1969), but with an endogenous risk aversion for the bank that depends on the state of its balance sheet, $k_{t}$, and takes into account the stochastic and partially controllable feature of deposits.

The bank's inability to fully control leverage is also important for understanding the distinct short- and long-term effects of regulatory changes. US regulators relaxed the SLR during the Covid-19 pandemic. Our model shows that this policy move stimulates lending and deposit-taking 
and is particularly effective in a low interest-rate environment. However, the effect is short-lived. The relaxed leverage regulation implies less frequent equity issuances over the long run. Given that the bank incurs issuance costs less often, it has a weaker incentive to boost earnings (through lending and deposit-taking) to compensate shareholders for paying issuance costs. In contrast, tightening leverage requirements discourages lending and deposit-taking in the short term, but over the long term, the bank must generate more earnings, reaching for yield by loading on risks in both lending and deposit-taking, to compensate for more frequent costly equity issuances.

Literature. A bank allows depositors to move funds freely in and out of their accounts. Therefore, the maturity of deposit contracts is not chosen by the bank, and it often depends on depositors' payment needs that are uncertain. ${ }^{9}$ Moreover, changes in the broader macroeconomic environment cause fluctuation in deposits as we saw during the Covid-19 pandemic. Therefore, deposit stock evolves stochastically over time. We develop a dynamic banking model that emphasizes this observation by incorporating the modeling insights from Merton (1969) and Leland (1994a).

Leland (1994a,b) model long-term debts with zero and a constant amortization rate, respectively, for nonfinancial corporations. ${ }^{10}$ Our model incorporates randomness into the duration of liabilities, which fits well how a bank's deposit liabilities evolve over time. A bank must carry its deposit liabilities indefinitely as long as its depositors do not withdraw. Recently, more attention has been drawn to the long duration of deposits (Drechsler, Savov, and Schnabl, 2021; Jermann and Xiang, 2021). After specifying the deposit law of motion, we model the rest of bank balancesheet management problem as portfolio problem (Merton, 1969), i.e., how to allocate the sum of equity and deposits. Equity, as a source of long-term funding, is a common state variable in models of financial intermediation that take portfolio problem approach (e.g., Holmström and Tirole, 1997; Gertler and Kiyotaki, 2010; He and Krishnamurthy, 2013; Brunnermeier and Sannikov, 2014; Rampini and Viswanathan, 2018), and this approach has received empirical support (Baron,

\footnotetext{
${ }^{9}$ In static settings, the literature explores the implications of payment risk on banks' liquidity holdings and incentive to lend (Freixas, Parigi, and Rochet, 2000; Donaldson, Piacentino, and Thakor, 2018; Parlour, Rajan, and Walden, 2020). Empirically, banks face large payment flow shocks (Furfine, 2000; Bech and Garratt, 2003; Afonso and Shin, 2011; Denbee, Julliard, Li, and Yuan, 2018; Choudhary and Limodio, 2017; Copeland, Duffie, and Yang, 2021).

${ }^{10}$ Nonfinancial firms' term debts are often approximated by debts with constant amortization rates (Leland, 1998; He and Xiong, 2012; Diamond and He, 2014; He and Milbradt, 2016; DeMarzo and He, 2021).
} 
Verner, and Xiong, 2020). Our model incorporates deposits as another important state variable.

Dynamic banking models often differentiate deposits and short-term bonds in their interest expenses and operation costs (Hugonnier and Morellec, 2017; Van den Heuvel, 2018; Begenau, 2020). In these models, banks do not face uncertainty in the size of deposit stock. Bianchi and Bigio (2014), De Nicolò, Gamba, and Lucchetta (2014), Bigio and Sannikov (2019), and Vandeweyer (2019) model deposits as one-period debts and deposit-flow shocks as intra-period shocks, so banks can freely adjust deposits every period without facing the problem of losing control of leverage.

A recent macro-finance literature recognizes deposits as means of payment (Piazzesi and Schneider, 2016; Drechsler, Savov, and Schnabl, 2018; Begenau and Landvoigt, 2018) but model deposits as short-term debts with yields reduced by a money premium (Stein, 2012; DeAngelo and Stulz, 2015; Krishnamurthy and Vissing-Jørgensen, 2015; Greenwood, Hanson, and Stein, 2015; $\mathrm{Li}, 2019$; Begenau, 2020). Brunnermeier and Sannikov (2016) is a notable exception. They model deposits as infinite-maturity nominal liabilities and study the Fisherian deflationary spiral.

The traditional banking models focus on bank runs when it comes to banks' commitment to allow depositors to withdraw funds without prior notice (e.g., Diamond and Dybvig, 1983; Allen and Gale, 2004; Goldstein and Pauzner, 2005). A key model ingredient is the illiquidity of bank assets, which causes the coordination failure among the depositors. Deposit outflow triggers inefficient liquidation of assets, but deposit inflow is not a concern. To distinguish our model from the literature, we allow the bank to freely adjust its assets so coordination failure does not happen. The deposit risk matters because the deposit shocks feed into the trajectory of bank leverage. Managing such risks is important under equity issuance costs and leverage requirements.

The key to our results is the bank's lack of control of deposit stock. The bank is endogenously averse to persistent deposit inflows that drive up leverage and cause costly equity issuance under leverage regulations. ${ }^{11}$ The relevance of equity issuance costs is supported by banks seeking ways

\footnotetext{
${ }^{11}$ While our model introduces the costs of issuing equity (Myers and Majluf, 1984), the link between equity and risk-taking capacity is more general. For example, it arises from agency friction (He and Krishnamurthy, 2012, 2013). Equity issuance costs are key ingredients in banking models (Bolton and Freixas, 2000; Bianchi and Bigio, 2014; Brunnermeier and Sannikov, 2014; Allen, Carletti, and Marquez, 2015; Nguyen, 2015; Phelan, 2016; Klimenko, Pfeil, Rochet, and Nicolo, 2016; Hugonnier and Morellec, 2017; Begenau, Bigio, Majerovitz, and Vieyra, 2019) and dynamic models of nonfinancial firms (Gomes, 2001; Riddick and Whited, 2009; Bolton, Chen, and Wang, 2011; Décamps, Mariotti, Rochet, and Villeneuve, 2011; DeAngelo, DeAngelo, and Whited, 2011; Hugonnier, Malamud,
} 
to avoid raising new equity in distress, for example, through the use of contingent capital (Pennacchi, 2010; Bolton and Samama, 2014; Glasserman and Nouri, 2016; Pennacchi and Tchistyi, 2018, 2019). We apply our model to understand the impact of relaxing leverage regulations during the Covid-19 pandemic. Moreover, we highlight deposit-rate adjustment as a way to partially control deposit flows. Such flexibility is limited in a low interest rate environment. Our analysis sheds light on how the level of interest rate can be critical for bank profitability and monetary policy transmission (Wang, 2018; Repullo, 2020; Brunnermeier, Abadi, and Koby, 2023).

Finally, our model delivers a rich set of empirical predictions, such as the connection between bank capital and valuation (Mehran and Thakor, 2011; Minton, Stulz, and Taboada, 2019), the connection between bank capital and risk-taking (Ben-David, Palvia, and Stulz, 2020), bank liability structure (Drechsler, Savov, and Schnabl, 2017), cyclicality in equity issuance and payout (Adrian, Boyarchenko, and Shin, 2015; Black, Floros, and Sengupta, 2016; Baron, 2020), comovement in loan growth and deposit rate (Ben-David, Palvia, and Spatt, 2017), and occasionally binding capital requirement (Gropp and Heider, 2010; Begenau et al., 2019).

\section{Model}

We model the decisions of a single bank that maximizes risk-neutral shareholders' value. ${ }^{12}$

Deposit dynamics. At the core of our model is the law of motion of deposits. We assume that the deposit stock at time $t$, which we denote by $X_{t}$, evolves as follows:

$$
d X_{t}=-X_{t}\left(\delta_{X} d t-\sigma_{X} d \mathcal{W}_{t}^{X}\right)+X_{t} n\left(i_{t}\right) d t
$$

where $\mathcal{W}_{t}^{X}$ is a standard Brownian motion. A key function of deposits is to serve as means of payment, which is why depositors should be able to move funds in and out of their accounts freely. and Morellec, 2015; Décamps, Gryglewicz, Morellec, and Villeneuve, 2017).

${ }^{12}$ Risk neutrality of the environment in our model shall be reinterpreted as post-risk-adjusted basis, i.e., under the risk-neutral measure by taking an equilibrium pricing kernel (stochastic discount factor), which depends on the aggregate dynamics of the macro-economy, as given. Then the risk-free rate, $r$, is the expected return under the risk-neutral measure of all financial assets that are traded by bank shareholders (Duffie, 2001). 
Payment activities expose the bank to random deposit flows. ${ }^{13}$ When the bank's depositors pay depositors in other banks, money flows out, $\left(\delta_{X} d t-\sigma_{X} d \mathcal{W}_{t}^{X}\right)>0$. When the depositors receive cash or electronic payments from other banks' depositors, money flows in, $\left(\delta_{X} d t-\sigma_{X} d \mathcal{W}_{t}^{X}\right)<$ $0 .{ }^{14}$ In practice, the magnitude of payments flows is large. The average weekly volume on Fedwire, the primary payment system in the U.S., is larger than U.S. GDP ( $\mathrm{Li}$ and Li, 2021). ${ }^{15}$

The bank can partially control deposit flows through the deposit rate, $i_{t}$. Lowering the deposit rate reduces deposit flows, i.e., $n^{\prime}\left(i_{t}\right)<0$. Let $r$ denote the risk-free rate. The bank may set the deposit rate $i_{t}$ below $r$, earning an interest rate spread. The response in deposit demand depends on the bank's market power (Drechsler, Savov, and Schnabl, 2017) and the convenience yield that agents derive from holding deposits as means of payment (Stein, 2012; DeAngelo and Stulz, 2015; Krishnamurthy and Vissing-Jørgensen, 2015; Nagel, 2016; Piazzesi and Schneider, 2016).

As in Drechsler, Savov, and Schnabl (2021), the deposit base in our model is sticky. Essentially, our model of deposits is similar to long-term debt with stochastic maturity. ${ }^{18}$ This way of modeling deposits stands in contrast with the macro-finance literature and the dynamic banking literature that generally treats deposits as short-term debt. ${ }^{19}$ In our model, when the bank adjusts the deposit rate, $i_{t}$, it causes a change in the deposit stock, $X_{t}$ of magnitude $d t^{20}$ This specification captures the well-documented inertia in depositors' decisions (Sharpe, 1997; Kiser, 2002; Kim,

\footnotetext{
${ }^{13}$ Freixas, Parigi, and Rochet (2000), Bianchi and Bigio (2014), Donaldson, Piacentino, and Thakor (2018), and Parlour, Rajan, and Walden (2020) study deposits as both banks' sources of funds and depositors' means of payment.

${ }^{14}$ The values of $\delta_{X}$ and $\sigma_{X}$ depend on the bank's position is in payment networks. The payment flow risk is significant in data (Afonso and Shin, 2011; Copeland, Duffie, and Yang, 2021; Li and Li, 2021).

${ }^{15}$ Recent evidence shows that the volatility in payment flows has implications on bank behavior in money markets and Treasury markets (Copeland, Duffie, and Yang, 2021) and affects bank lending ( $\mathrm{Li}$ and $\mathrm{Li}, 2021$ ).

Beyond payment activities, the specification captures other sources of deposit flows, for example, caused by changes in the broader economic environment. During the Covid-19 pandemic, banks experienced large deposit inflows in Europe and the U.S. due to forced savings and fiscal and monetary stimulus. ${ }^{16}$ This episode can be interpreted in our model as a sequence of realized positive shocks. We will explore how such deposit inflows pose challenges to bank balance-sheet management, a topic that has been actively discussed among practitioners and regulators. ${ }^{17}$

${ }^{18} \mathrm{He}$ and Manela (2016) model the withdrawal dynamics of depositors under the illiquidity of bank assets. Related, Jermann and Xiang (2021) model withdrawal from depositors' cash needs. In our model, bank assets are liquid and we directly model the aggregated behavior of deposit stock coming from a diversified depositor base.

${ }^{19}$ There exists a broad empirical literature on the measurement of duration of bank assets and liabilities (Begenau, Piazzesi, and Schneider, 2015; English, Van den Heuvel, and Zakrajšek, 2018; Begenau and Stafford, 2021).

${ }^{20}$ When the bank increases the deposit rate, it is likely to attract the attention of some depositors and therefore some deposit inflows, but it is not likely that all depositors respond at once, causing a jump in $X_{t}$ within $d t$; likewise, a low deposit rate may encourage some depositors to move money away but not all depositors respond immediately.
} 
Kliger, and Vale, 2003; Hannan and Adams, 2011) that translates into bank deposit market power (Drechsler, Savov, and Schnabl, 2017). In our calibration, the term, $n\left(i_{t}\right)$, is on average greater than $\delta_{X}$, resulting in exponential growth in $X_{t}$. This is in line with the data. Bank deposit stocks grow over time often in line with the broader economy, although deposit growth rates can vary within a range. Finally, any variation in $i_{t}$ has a persistent impact on the level of $X_{t}$ and implications on the future growth of deposits as a source of financing for the bank. This model captures in a simple way the role of the deposit rate in affecting the bank's deposit franchise. As we will shown in the next section, $X_{t}$ is a key state variable that drives the bank's value function.

Bank equity and earnings. We denote the bank's book equity at time $t$ by $K_{t}$. Besides equity, the bank relies on deposits to finance its asset, so that its long-term funding base is given by, $K_{t}+X_{t}$. denote the (mark-to-market) value of bank loans and other risky assets at time $t$ by $A_{t}$. The value of risky assets evolves as follows:

$$
d A_{t}=A_{t}\left(r+\alpha_{A}\right) d t+A_{t} \sigma_{A} d \mathcal{W}_{t}^{A}
$$

The parameter $\alpha_{A}$ reflects the excess return from lending expertise. ${ }^{21}$ The second term includes $\sigma_{A}$, the diffusion-volatility parameter, and a standard Brownian shock, representing unexpected loan charge-offs. ${ }^{22}$. We denote by $\phi d t$ the instantaneous covariance between $d \mathcal{W}_{t}^{X}$ and $d \mathcal{W}_{t}^{A}$.

The bank may issue short-term bonds to increase funding beyond $K_{t}+X_{t}$. Let $B_{t}$ denote the value of short-term wholesale funding (bonds that the bank issues at $t$ and that mature at $t+d t$ ). Combining short-term and long-term funding, we obtain the following accounting identity:

$$
K_{t}+X_{t}+B_{t}=A_{t}
$$

We will impose throughout our analysis capital requirements and leverage regulation such that the

\footnotetext{
${ }^{21}$ The bank may have expertise in monitoring (Diamond, 1984), loan screening (Ramakrishnan and Thakor, 1984), relationship lending (Boot and Thakor, 2000), restructuring (Bolton and Freixas, 2000), asset management and diversification (He and Krishnamurthy, 2012, 2013; Brunnermeier and Sannikov, 2014, 2016), collateralization (Rampini and Viswanathan, 2018), and serving local credit markets (Gertler and Kiyotaki, 2010).

${ }^{22}$ We add jump risk in Appendix B as Parlour, Stanton, and Walden (2012); Hugonnier and Morellec (2017)
} 
bank does not default on its debt liabilities. Therefore, when $B_{t}>0$, the bank pays the risk-free rate, and its interest expense over $d t$ is given by $B_{t} r d t$. Equally, when $B_{t}<0$, the bank holds bonds issued by other entities (e.g., the government) and earn the risk-free rate $r$.

The law of motion of bank equity $K_{t}$ is given by

$$
d K_{t}=A_{t}\left[\left(r+\alpha_{A}\right) d t+\sigma_{A} d \mathcal{W}_{t}^{A}\right]-B_{t} r d t-X_{t} i_{t} d t-C\left(n\left(i_{t}\right), X_{t}\right) d t-d U_{t}+d F_{t}
$$

where the first four terms constitute bank earnings - the return on risky investment minus interest expenses on bonds and deposits and minus the flow cost, $C\left(n\left(i_{t}\right), X_{t}\right) d t$, which represents the expenses of maintaining the existing deposit franchise and of serving new customers $\left(\frac{\partial C\left(n\left(i_{t}\right), X_{t}\right)}{\partial n\left(i_{t}\right)}>\right.$ 0 and $\left.\frac{\partial C\left(n\left(i_{t}\right), X_{t}\right)}{\partial X_{t}}>0\right)$ (Hugonnier and Morellec, 2017; Drechsler, Savov, and Schnabl, 2021). We use $U_{t}$ to denote cumulative dividends, so that the (non-negative) incremental payout is $d U_{t}$. The bank can issue equity. Let $F_{t}$ denote the bank's cumulative equity financing up to time $t$.

Given the sources of long-term funding, $X_{t}$ and $K_{t}$, the bank's choices of $A_{t}$ and $B_{t}$ resemble a portfolio problem (Merton, 1969). Let $\pi_{t}^{A}$ denote the portfolio weight on loans and other risky assets, $\pi_{t}^{A}\left(X_{t}+K_{t}\right)=A_{t}$. The weight on bonds is accordingly $\left(\pi_{t}^{A}-1\right)$ from (3). With this notation, we can then rewrite (4) as follows:

$$
d K_{t}=\left(X_{t}+K_{t}\right)\left[\left(r+\pi_{t}^{A} \alpha_{A}\right) d t+\pi_{t}^{A} \sigma_{A} d \mathcal{W}_{t}^{A}\right]-X_{t} i_{t} d t-C\left(n\left(i_{t}\right), X_{t}\right) d t-d U_{t}+d F_{t}
$$

Equity issuance costs. In reality, banks face external financing costs due to asymmetric information, incentive issues, and transaction costs. A large empirical literature has sought to measure these costs, in particular, the costs arising from the negative stock price reaction to the announcement of a new equity issue. ${ }^{23}$ Let $H_{t}$ denote the cumulative costs of equity issuance up to time $t$.

\footnotetext{
${ }^{23}$ Explicitly modeling informational asymmetry would result in a substantially more involved analysis. Lucas and McDonald (1990) provide a tractable analysis under assumption that the informational asymmetry lasts one period. Lee, Lochhead, Ritter, and Zhao (1996) document that for initial public offerings (IPOs), the direct costs (underwriting, management, legal, auditing and registration fees) average $11.0 \%$ of the proceeds, and for seasoned equity offerings (SEOs), 7.1\%. IPOs also incur a substantial indirect cost due to short-run underpricing. An early study by Asquith and Mullins (1986) found that the average stock price reaction to the announcement of a common stock issue was $-3 \%$ and the loss as a percentage of the new issue size was as high as -31\% (Eckbo, Masulis, and Norli, 2007).
} 
The bank's objective function can then be written as the maximization of shareholder value:

$$
V_{0}=\max _{\{A, B, i, U, F\}} \mathbb{E}\left[\int_{t=0}^{\tau} e^{-\rho t}\left(d U_{t}-d F_{t}-d H_{t}\right)\right]
$$

We assume that $\rho>r$, a common assumption in dynamic corporate finance and macro-finance models, e.g., DeMarzo and Sannikov (2006), DeMarzo and Fishman (2007), and Brunnermeier and Sannikov (2014) among others. ${ }^{24}$ We denote by $\tau$ the stochastic stopping time when the bank is closed. Regulators shut down the bank when it violates the following regulatory requirements.

Capital Requirement. Following Nguyen (2015), Davydiuk (2017), Van den Heuvel (2018), and Begenau (2020), we introduce equity capital requirements as follows:

$$
\frac{A_{t}}{K_{t}} \leq \xi_{K}
$$

In accordance with Basel III capital standards, the bank must maintain a minimal ratio of capital to risk-weighted assets of $7 \% .{ }^{25}$ Accordingly, we set $\xi_{K}$ equal to $1 / 0.07=14.3 .^{26}$

Leverage regulation. The bank is also subject to a maximum leverage requirement, which for simplicity we take to be the supplementary leverage ratio (SLR): When the bank issues bonds, so that $B_{t}>0$, the SLR takes the same form as the equity capital requirement:

$$
\frac{A_{t}}{K_{t}}=\frac{K_{t}+X_{t}+B_{t}}{K_{t}} \leq \xi_{L}
$$

\footnotetext{
${ }^{24}$ Impatience induces payout; otherwise, the bank never pays out dividends and always accumulates financial slack (equity) to avoid the refinancing costs. This impatience can be microfounded by an exogenous Poisson exit rate $\rho-r$.

${ }^{25}$ See Thakor (2014) for a review of the debate on bank capital and its regulations.

${ }^{26}$ Davydiuk (2017) and Begenau (2020) set $\xi_{K}$ to be the sample average of the ratio of Tier 1 equity to risky assets for the reason that banks typically maintain a buffer to prevent regulatory corrective action. In our model, the buffer arises endogenously, so we set $\xi_{K}$ to the regulatory threshold. In theoretical studies on banking regulations, De Nicolò, Gamba, and Lucchetta (2014) calibrate the capital requirements to $4 \%$ and $12 \%$, Hugonnier and Morellec (2017) calibrate the thresholds to $4 \%, 7 \%, 9 \%$, and $20 \%$ to investigate the effects of the proposal by Admati and Hellwig (2013), and Phelan (2016) calibrates the threshold to $7.7 \%$ and $10.6 \%$ in a macroeconomic model.
} 
when $B_{t}<0$, the SLR requirement is given by

$$
\frac{A_{t}-B_{t}}{K_{t}}=\frac{K_{t}+X_{t}}{K_{t}} \leq \xi_{L}
$$

U.S. bank holding companies that have been designated as global systemically important banks must maintain an inverse supplementary leverage ratio (SLR) that is greater than 5\% (i.e., $\xi_{L}=20$ ).

The SLR requirement has attracted a lot of attention from practitioners and regulators during the Covid-19 pandemic when banks in the U.S. saw trillions of dollars of deposit inflows. An increase in $X_{t}$ tightens the SLR constraint and may trigger costly equity issuance. U.S. banking regulators recognized that deposit inflows put pressure on banks and relaxed the SLR requirement in 2020. ${ }^{27}$ However, these exemptions lapsed in April 2021, and banks again faced the threat of a binding SLR. In response, banks have encouraged depositors to move their money to money market funds that in turn invest in the reverse repo facility at the Federal Reserve. ${ }^{28}$ Indeed, following the end of SLR exemption, the outstanding amount of reverse repo increased dramatically from almost zero to one trillion dollars within three months (see Figure D. 1 in the appendix). ${ }^{29}$

The SLR requirement represents the U.S. implementation of the Basel III Leverage Ratio. During the Covid-19 pandemic, European banks faced similar challenges of complying with their versions of leverage regulations under massive deposit inflows. ${ }^{30}$ In the U.S., the SLR requirement is imposed on large banks. ${ }^{31}$ Beyond the SLR, US banks have long been subject to a requirement on the ratio of Tier 1 capital to total consolidated assets ("U.S. leverage ratio"). The difference between the SLR and U.S. leverage ratio is that the former accounts for both on- and certain off-

\footnotetext{
${ }^{27}$ See "Fed's Powell makes case why Congress should relax bank capital rule" by Hannah Lang, American Banker July 29, 2020. The SLR requirement was likely binding during this period of time as it also affected the functioning of Treasury market (He, Nagel, and Song, 2021).

${ }^{28}$ See "Cash-rich US banks move to reduce corporate deposits" by Imani Moise, Financial Times May 3, 2021. See also, "Banks to Companies: No More Deposits, Please" by Nina Trentmann, Wall Street Journal June 9, 2021.

${ }^{29}$ At the onset of Covid-19 crisis, there was already a spike in reverse repo usage as banks started receiving deposit inflows. Under the SLR exemption, deposit inflows would no longer cause costly equity issuance, the reverse repo facility was not well utilized. The outstanding amount of reverse repo ran up quickly after the end of SLR exemption.

${ }^{30}$ See "Banks in Germany Tell Customers to Take Deposits Elsewhere" By Patricia Kowsmann, Wall Street Journal March 1, 2021.

${ }^{31}$ National and state banks, savings associations, BHCs and savings and loan holding companies (together, "banking organizations") with $\$ 250$ billion in total consolidated assets or $\$ 10$ billion of on-balance sheet foreign exposures.
} 
balance sheet assets and exposures, whereas the latter only measures on-balance sheet items. The denominator in these leverage ratios is total assets without risk adjustment, so it is distinct from the risk-based capital requirement. A leverage cap is deemed important by regulators in part because the risk-based capital requirement can be vulnerable to manipulation (Plosser and Santos, 2014).

\section{Dynamic Banking}

The bank's balance sheet management problem and financial decisions amount to solving a dynamic optimization problem with two state variables (the stock of deposits $X_{t}$ and the stock of equity capital $K_{t}$ ) and five control variables, the size of the loan book and other risky investments $A_{t}$, the amount of bond issuance $B_{t}$, the deposit rate $i_{t}$, the payout to shareholders $d U_{t}$, and the size of equity issuance $d F_{t}$. We denote the bank shareholder value function as $V_{t}=V\left(X_{t}, K_{t}\right)$. Given the recursive nature of the optimization problem, we suppress time subscripts going forward.

\subsection{Bank Optimization}

Homogeneity and the HJB equation. For tractability it is helpful to parameterize the cost of serving the depositor base $C(n(i), X)$ as $C(n(i), X)=c(n(i)) X$, where $c(\cdot)$ is an increasing and convex function, and we assume that the equity issuance costs depend on both the issuance amount and the size of the bank, $d H=\psi_{1} d F+\psi_{0} X$. Given these functional forms, the bank's problem has a homogeneity property that significantly simplifies the analysis and allows for an intuitive representation of our results. Specifically, the value function can be written as $V(X, K)=$ $v(k) X$, where

$$
k \equiv \frac{K}{X}
$$

The derivatives of value function $V(X, K)=v(k) X$ with respect to $K$ and $X$ are then given by

$$
\begin{aligned}
& V_{K}(X, K)=v^{\prime}(k), V_{X}(X, K)=v(k)-v^{\prime}(k) k \\
& V_{K K}(X, K)=v^{\prime \prime}(k) \frac{1}{X}, V_{X X}(X, K)=v^{\prime \prime}(k) \frac{k^{2}}{X}, V_{X K}(X, K)=-v^{\prime \prime}(k) \frac{k}{X} .
\end{aligned}
$$


Importantly, we will focus on the marginal value of equity, $v^{\prime}(k)$ (the equity marginal $q$ ) and the marginal value of deposits (the deposit marginal $q$ ), $v(k)-v^{\prime}(k) k$, in our analysis.

We show that the bank pays out dividends and raises equity at respectively upper and lower boundaries for $k$, denoted by $\bar{k}$ and $\underline{k}$, respectively. Within these two boundaries for $k$ (i.e., when $d F=0$ and $d H=0)$, the HJB equation for the $X$-scaled value function, $v(k)$, is given by

$$
\begin{aligned}
\rho v(k)=\max _{\pi^{A}, i} & {\left[v(k)-v^{\prime}(k) k\right]\left[-\delta_{X}+n(i)\right]+\frac{1}{2} v^{\prime \prime}(k) k^{2} \sigma_{X}^{2} } \\
& +v^{\prime}(k)(1+k)\left(r+\pi^{A} \alpha_{A}\right)+\frac{1}{2} v^{\prime \prime}(k)(1+k)^{2}\left(\pi^{A} \sigma_{A}\right)^{2} \\
& -v^{\prime}(k)[i+c(n(i))]-v^{\prime \prime}(k) k(1+k) \pi^{A} \sigma_{A} \sigma_{X} \phi .
\end{aligned}
$$

In the next subsections, we show that optimal choices of $\pi^{A}$ and $i$ are univariate functions of $k$, so that equation (11) is an ordinary differential equation (ODE) for $v(k) .{ }^{32}$ If the bank issues bonds (i.e., $B>0$ or $\pi^{A}>1$ ), the capital requirement (7) and SLR requirement (8) both impose restrictions on $A / K$, so that the bank faces the constraint $A / K \leq \min \left\{\xi_{K}, \xi_{L}\right\}$ or

$$
\pi^{A} \leq \min \left\{\xi_{K}, \xi_{L}\right\}\left(\frac{K}{X+K}\right)=\min \left\{\xi_{K}, \xi_{L}\right\}\left(\frac{k}{1+k}\right)
$$

If the bank instead holds bonds (i.e., $B \leq 0$ or $\pi^{A} \leq 1$ ), the capital requirement (7) reduces to the restriction for $\pi^{A}$,

$$
\pi^{A} \leq \xi_{K}\left(\frac{k}{1+k}\right)
$$

and the SLR requirement is now given by (9) instead of (8), which sets a lower boundary for $k$,

$$
\frac{X+K}{K} \leq \xi_{L}, \text { or equivalently, } k \geq \underline{k} \equiv \frac{1}{1-\xi_{L}^{-1}}-1
$$

\footnotetext{
${ }^{32}$ The unscaled HJB equation for the value function, $V(X, K)$, is given by

$\rho V(X, K)=\max _{\left\{\pi^{A}, i\right\}} V_{X}(X, K) X\left[-\delta_{X}+n(i)\right]+\frac{1}{2} V_{X X}(X, K) X^{2} \sigma_{X}^{2}+V_{K}(X, K)(X+K)\left(r+\pi^{A} \alpha_{A}\right)$

$+\frac{1}{2} V_{K K}(X, K)(X+K)^{2}\left(\pi^{A} \sigma_{A}\right)^{2}-V_{K}(X, K)[X i+C(n(i), X)]+V_{X K}(X, K) X(X+K) \pi^{A} \sigma_{A} \sigma_{X} \phi$.
} 
Our numerical solution shows that when $k$ is low, the optimal portfolio policy for the bank is such that $B<0$ (or equivalently, $\pi^{A}<1$ ), so that $\underline{k}$ in (14) is the lower boundary of $k$. Intuitively, when equity capital is low relative to deposit liabilities (i.e., when leverage is high), the bank holds bonds as risk-free assets rather than increasing leverage further via wholesale funding. The state variable $k$ can fall to $\underline{k}$ following negative return shocks to risky assets (i.e., $d \mathcal{W}_{t}^{A}<0$ ) or positive shocks to deposits (i.e., $d \mathcal{W}_{t}^{X}>0$ ). To comply with the leverage regulation (14), the bank then raises external equity. Let $m \equiv d F / X$ denote the issuance amount scaled by $X$. The optimality of issuance implies the following boundary conditions. The marginal value of equity is equal to the marginal dilution cost

$$
v^{\prime}(\underline{k}+m)=1+\psi_{1} .
$$

Second, existing shareholders' pre- and post-issuance values must be the same

$$
v(\underline{k}+m)-v(\underline{k})=\psi_{0}+\left(1+\psi_{1}\right) m .
$$

Note that leverage regulation plays a different role from risk-based capital requirement. Traditionally, regulators rely on the capital requirement to trigger equity issuance, but this only works if the bank cannot freely adjust $A$ (i.e., the risky assets are illiquid). For simplicity, we allow the bank to freely adjust $A$, so that the capital requirement only constrains risk-taking, $\pi^{A}$, which is a control variable, but does not trigger equity issuance directly. In contrast, the leverage regulation specifies a lower bound on the state variable $k$ and can trigger equity issuance. As bank assets become increasingly liquid over time (for example, through securitization), it is to be expected that leverage regulation becomes increasingly important as a way to induce equity raising. ${ }^{33}$

Next, we analyze the bank's payout decision. Let $\bar{k}$ denote the payout boundary of $k$. The optimality of a payout implies that

$$
v^{\prime}(\bar{k})=1,
$$

i.e., the marginal value of retaining equity is equal to one, the marginal value of a payout. The

\footnotetext{
${ }^{33}$ Therefore, the importance of leverage regulation goes beyond supplementing the risk-based capital requirement that is vulnerable to manipulation (Plosser and Santos, 2014).
} 
optimality of a payout also requires the following super-contact condition (Dumas, 1991) to hold:

$$
v^{\prime \prime}(\bar{k})=0
$$

We will show that our numerical solution of $v(k)$ is concave, so that (15) and (17) imply that the bank pays out dividends when $k$ is high and raises equity when $k$ is low, i.e., $\bar{k}>\underline{k}$. Given $\underline{k}$ in (14), the boundary conditions (15)-(18) and second-order ODE (11) determine a solution for $v(k)$, the optimal issuance amount $m$, and the upper (dividend payout) boundary $\bar{k}$. Note that the payout amount is determined as follows: At $\bar{k}$, any positive shock to $K$ (numerator of $k$ ) or negative shock to $X$ (denominator of $k$ ) trigger a payout, and the payout amount (i.e., the reduction in $K$ ) is the amount needed to bring down $k$ to $\bar{k}$. In other words, $\bar{k}$ is a reflecting boundary of $k$. Note that this solution structure is akin to the structure for dynamic models of corporate investment and liquidity management under equity issuance costs (e.g., Bolton, Chen, and Wang, 2011; Décamps, Mariotti, Rochet, and Villeneuve, 2011; Décamps, Gryglewicz, Morellec, and Villeneuve, 2017).

In Appendix A, we provide a richer setup where, as in Drechsler, Savov, and Schnabl (2018), the bank holds reserves and is subject to a regulatory reserve requirement. In this setup, our results on the value of deposits, optimal payout, equity issuance, risk-taking, and deposit rate still hold. ${ }^{34}$ The only difference is that the reserve requirement generates another lower bound for $k$. In short, the bank raises equity either to meet the SLR requirement at $\underline{k}$ given by (14) or when the reserve requirement binds. Following the financial crisis, the liquidity coverage ratio requirement has replaced the role of reserve requirements with a broader set of high quality liquid assets (HQLA) that can be easily traded intraday to settle interbank payments and other liquidity needs. ${ }^{35}$

\footnotetext{
${ }^{34}$ Our solution of optimal reserve holdings resembles the classic money demand (Baumol, 1952; Tobin, 1956).

${ }^{35}$ Liquidity requirement in our model triggers costly equity issuance and thus its role is different from that in models that emphasize the illiquidity of bank assets (Diamond and Kashyap, 2016; Carletti, Goldstein, and Leonello, 2019).
} 


\subsection{Optimal Risk Taking}

From the HJB equation (11), we can solve for $\pi^{A}$. From the optimality condition $\frac{A}{K}=\frac{\pi^{A}(X+K)}{K}=$ $\pi^{A}\left(\frac{1+k}{k}\right)$, we obtain the solution for the risky asset-to-capital ratio (within the capital requirement):

$$
\frac{A}{K}=\frac{\alpha_{A}}{\gamma(k) \sigma_{A}^{2}}+\frac{\sigma_{X}}{\sigma_{A}} \phi
$$

In (19), $\gamma(k)$ is a measure of endogenous risk aversion based on the value function:

$$
\gamma(k) \equiv-\frac{v^{\prime \prime}(k) k}{v^{\prime}(k)}
$$

This solution resembles Merton's portfolio choice solution, which includes both a meanvariance term and a hedging-demand term. In the numerator, a higher excess return, $\alpha_{A}$, increases lending. The bank's risk-taking is state-dependent through $\gamma(k)$. Even though equityholders' have a risk-neutral preference, the bank is endogenously risk-averse, i.e., $\gamma(k)>0$, due to the equity issuance costs. ${ }^{36}$ When $\gamma(k)$ is low, the bank chooses a high loan-to-capital ratio; when $\gamma(k)$ is high, the bank reduces its risk exposure. Our numerical solution shows that $\gamma^{\prime}(k)<0$.

The bank's incentive to lend is also strengthened when deposits are natural hedges for the asset-side shock, $d \mathcal{W}^{A}$. In our model, the liability-side (deposit) shocks and asset-side shocks are positively correlated $(\phi>0)$. The deposit risk is essentially the bank's background risk from the perspective of portfolio management. When $\phi>0$, it captures the synergy between lending and deposit-taking that has been studied extensively in the banking literature (e.g., Calomiris and Kahn, 1991; Berlin and Mester, 1999; Kashyap, Rajan, and Stein, 2002; Gatev and Strahan, 2006; Hanson, Shleifer, Stein, and Vishny, 2015). This hedging benefit also echoes the findings of Drechsler, Savov, and Schnabl (2021) that financing loans with deposits helps banks to hedge risk. ${ }^{37}$

\footnotetext{
${ }^{36}$ If shareholders are risk averse, we can reinterpret the optimization problem as done under the risk-neutral measure, taking as given the shareholders' stochastic discount factor that dictates the change of measure between the physical measure and risk-neutral measure.

${ }^{37}$ The finding of Drechsler, Savov, and Schnabl (2021) focuses on interest-risk risk.
} 


\subsection{Q-theory of Deposit Taking}

Optimal deposit rate. From the HJB equation (11), we obtain the first-order condition for $i$ :

$$
\left[v(k)-v^{\prime}(k) k\right] n^{\prime}(i)=v^{\prime}(k)\left[1+c^{\prime}(n(i)) n^{\prime}(i)\right]
$$

Recall that the marginal value of deposits (the deposit marginal $q$ ), equals $\left[v(k)-v^{\prime}(k) k\right]$ under the functional form $V(X, K)=v(k) X$, and the marginal value of equity equals $v^{\prime}(k)$. The left side of the first-order condition is the marginal benefit of raising the deposit rate to attract more deposits. The increase in deposits, $n^{\prime}(i)$, is valued at the deposit marginal $q$. The right side is the marginal cost due to reduction in earnings (and the associated slowdown of equity capital accumulation). The impact of higher interest expenses and the marginal cost of serving a larger depositor base are multiplied by the marginal value of equity.

For simplicity, we specify the following functional form for $n(i)$ :

$$
n(i)=\omega_{0}+\omega_{1}(i-r)
$$

This is in line with the evidence that deposit demand is driven by the interest rate spread between the deposit rate and the prevailing interest rate (Lucas and Nicolini, 2015; Nagel, 2016; Drechsler, Savov, and Schnabl, 2017). Depositors compare the deposit rate with $r$ and deposit more when $i$ increases. When $i$ is below $r$, depositors incur a carry cost of holding deposits, so that they tend to reduce deposits. ${ }^{38} \mathrm{We}$ let the cost of serving depositors take the following simple quadratic form

$$
c(n(i))=\frac{\theta}{2} n(i)^{2}
$$

From the HJB equation (11), we can then derive the following formula for the optimal deposit rate:

$$
i=r+\frac{\frac{V_{X}(X, K)}{V_{K}(X, K)}-\frac{1}{\omega_{1}}}{\omega_{1} \theta}-\frac{\omega_{0}}{\omega_{1}}=r+\frac{\left(\frac{v(k)-v^{\prime}(k) k}{v^{\prime}(k)}\right)-\frac{1}{\omega_{1}}}{\omega_{1} \theta}-\frac{\omega_{0}}{\omega_{1}} .
$$

\footnotetext{
${ }^{38} \mathrm{We}$ also experiment with an alternative specification of quadratic $n(i)$ that allows the deposit flow to be increasingly sensitive to deposit rate as $i$ approaches zero. The results are very similar and are available upon request.
} 
When the bank increases $i_{t}$, it obtains new deposits with a marginal value $V_{X}(X, K)$, but it also increases interest expenses and the costs of serving depositors that reduce earnings and equity with marginal value $V_{K}(X, K)$. Therefore, the optimal deposit rate increases in $\frac{V_{X}(X, K)}{V_{K}(X, K)}$. When deposits are more valuable relative to equity, the bank raises $i_{t}$. The sensitivity of deposit flows to the deposit rate, captured by $\omega_{1}$, has an overall ambiguous impact on $i$. Different deposit products may have different demand elasticities, and some depositors may be more attentive and responsive to the deposit rate than others. Aggregating different deposit types and depositor types to the bank level, we obtain $\omega_{1}$, the overall sensitivity of deposit flows to the deposit rate. ${ }^{39}$

The optimal policy for deposit rate setting resembles the structure of the optimal investment policy in the q-theory literature. In Hayashi (1982), nonfinancial firms make investments in productive capital, with Tobin's q (the marginal value of capital) dictating the optimal decision. In our model, the optimal deposit rate depends on both the deposit marginal q, $V_{X}(X, K)$, and the equity marginal q, $V_{K}(X, K) .{ }^{40}$ Raising the deposit rate can be viewed as the bank's decision to build up the deposit stock, $X_{t}$, that finances its current asset holdings. The law of motion of $X_{t}$ indicates geometric growth, so the current change of $X_{t}$ has persistent effect on future level. Therefore, We may also interpret an increase in $X_{t}$ as the accumulation of customer capital (as a larger deposit base is often associated with more depositors) and the build-up of future source of financing.

Negative deposit marginal $q$. Another difference between our optimal deposit rate policy and the q-theory of investment is that the deposit marginal $q, V_{X}(X, K)$, can turn negative when the bank is undercapitalized (i.e., $k$ is low) and close to hitting the equity issuance boundary $\underline{k}$. When $k$ is high, the deposit stock, $X_{t}$, is a source of profits (as the bank earns the deposit spread, $r-i_{t}$ ) and plays the role of "productive capital" for the bank. However, when $k$ is close to $\underline{k}$, another economic force dominates: Any further increase in deposits pushes $k$ even lower and makes costly equity issuance more likely. Therefore, the deposit marginal $q, V_{X}(X, K)$, can turn negative.

\footnotetext{
${ }^{39}$ Figure D.3 in the appendix provides comparative statics for $\omega_{1}$ and shows the robustness of our results. Under a more elastic deposit demand (i.e, a higher $\omega_{1}$ ), the bank enjoys less market power and therefore sets a higher deposit rate. Moreover, the deposit marginal $q$ declines when $\omega_{1}$ increases.

${ }^{40}$ Related, Bolton, Chen, and Wang (2011) find the ratio of marginal value of productive capital to the marginal value of cash drives a firm's investment under adjustment costs. Kargar, Passadore, and Silva (2020) find the ratio of marginal value of a subset of assets to the marginal value of wealth drives portfolio decisions under transaction costs.
} 
The key to our mechanism is the link between deposit inflows and costly equity issuance. The equity issuance boundary $\underline{k}$ is given by the leverage requirement (SLR in our baseline model). Other regulations have the same effect. For example, under the Interstate Act, banks are required to maintain a minimum level of loan-to-deposit ratio. ${ }^{41}$ In Ohio, for every $\$ 100$ deposits raised, a bank must extend loans worth at least $\$ 76$ in Ohio. Such a loan-to-deposit ratio requirement is equivalent to the condition

$$
A_{t} \geq \xi_{X} X_{t}
$$

where $\xi_{X}$ is 0.76 in Ohio, but differs by states. ${ }^{42}$ As we show in the numerical solution, when the bank is undercapitalized, it scales back risk-taking, reducing $A_{t}$, so that this constraint binds when $k$ is low and any deposit inflow forces an increase in $A_{t}$. Under this alternative constraint the risk-based capital requirement can trigger costly equity issuance. Substituting $A_{t}=\xi_{X} X_{t}$ into the capital requirement (7), we obtain

$$
\xi_{X} X_{t} \leq \xi_{K} K_{t}, \text { or equivalently, } k_{t} \geq \frac{\xi_{X}}{\xi_{K}}
$$

which gives us a lower (equity issuance) bound on $k_{t}$. For example, under $\xi_{X}=0.76$ and $\xi_{K}=$ 14.7 in (7), the lower bound of $k_{t}$ is 0.052 , which is close to the lower bound of 0.05 from the SLR. Therefore, even without the SLR, an undercapitalized bank may be forced to raise equity and pay the issuance costs because deposit inflows lead to more lending under the loan-to-deposit ratio requirement, so that the equity capital requirement triggers equity issuance.

Zero lower bound. When the deposit marginal $q$ declines, the bank lowers $i_{t}$ to turn away unwanted deposits, as shown in (24). However, banks rarely set negative deposit rates in practice. In the recent low interest rate environment, the bunching of deposit rates at zero has become a salient

\footnotetext{
${ }^{41}$ Congress enacted section 109 to ensure that interstate branches would not take deposits from a community without the bank's reasonably helping to meet the credit needs of that community. Interagency regulations implementing section 109 became effective in October 1997. Please refer to section 109 of the Riegle-Neal Interstate Banking and Branching Efficiency Act of 1994 at https://www.occ.gov/news-issuances/news-releases/2021/nr-ia-2021-59a.pdf

${ }^{42}$ The median across states is 0.835 , the minimum 0.45 (Virgin Islands), and the maximum 1.02 (New Jersey). Among the top three states by GDP, California requires 0.8, New York 0.85, and Texas 0.76 .
} 
empirical feature (Heider, Saidi, and Schepens, 2019). Accordingly, we impose a zero lower bound on the deposit rate, $i_{t} \geq 0$. The zero lower bound makes it more difficult for the bank to manage deposits, because once $i_{t}$ reaches zero, the bank cannot reduce the deposit rate further to curtail deposit inflows. This problem was relevant during the Covid-19 pandemic when deposit inflows occurred alongside with near-zero deposits rates.

Banks are reluctant to set negative deposit rates for several reasons. A negative deposit rate is an uncharted territory and may attract depositors' attention, triggering a sudden withdrawal by an unpredictable amount. After all, depositors can theoretically hold physical bills of fiat money. Deposit withdrawals en masse seem to solve the problem of unwanted deposits, but to meet a high volume of withdrawals, the bank will have to liquidate assets at short notice and at a hefty discount. In other words, setting a negative deposit rate and triggering a large withdrawal may help the bank avoid paying the equity issuance costs in compliance of the SLR, but it may cause a new problem of costly asset liquidation. In Section 6.1, we remove the zero lower bound and accommodate the aforementioned mechanism. The results are similar to those in our baseline model.

Beyond the concern over large withdrawals, consumer protection laws make it difficult for banks to effectively set negative deposit rates via charging various fees. There are also other considerations outside of our model that go against setting negative deposit rates. For example, after depositors withdraw money in response to a negative rate, it is difficult to rebuild customer base, which can be costly later when the bank becomes better capitalized and needs deposits as a source of financing. Note that our specification of the law of motion of $X_{t}$ already reflects the idea of customer capital as the current variation in $X_{t}$ has permanent effect under geometric growth. A decline in $X_{t}$ lowers the future trajectory of $X_{t}$. A negative deposit rate may amplify the destruction of customer capital on top of this channel. 
Table 1: PARAMETER VALUeS

This table summarizes the parameter values for our baseline analysis. The unit of time is year.

\begin{tabular}{lcc} 
Parameters & Symbol & Value \\
\hline risk-free rate & $r$ & $1 \%$ \\
discount rate & $\rho$ & $4.5 \%$ \\
bank excess return & $\alpha_{A}$ & $0.2 \%$ \\
asset return volatility & $\sigma_{A}$ & $10 \%$ \\
deposit flow (mean) & $\delta_{X}$ & 0 \\
deposit flow (volatility) & $\sigma_{X}$ & $8 \%$ \\
deposit demand (constant) & $\omega_{0}$ & 0.06 \\
deposit demand (rate sensitivity) & $\omega_{1}$ & 9 \\
deposit maintenance cost & $\theta$ & 0.5 \\
corr. between deposit and asset shocks & $\phi$ & 0.8 \\
equity issuance fixed cost & $\psi_{0}$ & $0.14 \%$ \\
equity issuance propositional cost & $\psi_{1}$ & $5.0 \%$ \\
SLR requirement parameter & $\xi_{L}$ & 20 \\
capital requirement parameter & $\xi_{K}$ & 14.3 \\
\hline
\end{tabular}

\section{Quantitative Analysis}

\subsection{Parameter Choices}

We report our choice of parameter values for the baseline solution in Table 4. We set the unit of time to be a year. The risk-free rate, $r$, is a key parameter. In the baseline model, we consider $r=1 \%$, and in Section 5.2 we compare the model solutions under $r=1 \%$ and $r=2 \%$. These values capture the interest rate environment in recent decades. From January 2020 to January 2023, the average Fed funds rate is $1.7 \%$, and in the period after the great recession (from July 2009 to January 2023), the average Fed funds rate is $0.6 \%$ (source: FRED). We set shareholders' discount rate $\rho$ to $4.5 \%$, in line with the commonly used value in dynamic corporate finance models. ${ }^{43} \mathrm{We}$ set $\alpha_{A}$ to $0.2 \%$ so that the model generates an average return on assets (ROA) of $1.04 \%$, close to the

\footnotetext{
${ }^{43}$ One example is Bolton, Chen, and Wang (2011). This is also consistent with the dynamic contracting literature (DeMarzo and Fishman, 2007; Biais, Mariotti, Plantin, and Rochet, 2007).
} 
average 1\% ROA of US banks in the last two decades (source: FRED). To calculate the average ROA and other averages later, we use the stationary distribution of $k .^{44}$ We set the asset return volatility, $\sigma_{A}$, to $10 \%$ as in Sundaresan and Wang (2014) and Hugonnier and Morellec (2017) ${ }^{45}$

The law of motion of the deposit stock $X_{t}$ given by equation (1) is at the center of the model. The calibration of the deposit-flow sensitivity to the deposit rate, $\omega_{1}$ in (22) targets the average deposit rate. Under $\omega_{1}=9$ in the baseline model, the model generates an average deposit rate of $0.28 \%$, which is in line with the post-GFC data (source: FRED). ${ }^{46}$ We set $\delta_{X}$ to zero, so the constant, $\omega_{0}$, in (22) accounts for the part of net deposit flow that is not sensitive to the deposit rate. The value of $\omega_{0}$ is set to 0.06 , so that the model generates an average deposit growth rate equal to $8.5 \%$ per year, close to the average bank's growth rate of $1.9 \%$ per quarter documented by Lin (2019). For the size of deposit-flow shock, $\sigma_{X}$, we choose 0.08 for the baseline model. In Figure D.2 in the appendix, we show that the results are similar under $\sigma_{X}=0.06$ and $\sigma_{X}=0.10$. These values are in line with the volatility of deposit growth rate documented by Lin (2019). ${ }^{47}$

The remaining parameters are calibrated as follows. The parameter $\theta$ for the cost of maintaining the deposit franchise, which we set to 0.5 , so that the model generates an average return on equity equal to $11 \%$ close to the average of $10 \%$ in the last two decades (source: FRED). The correlation between the asset-side and liability-side (deposit) shocks, $\phi$, is set to 0.8 , so that the average deposit-to-total liabilities (or assets) ratio is equal to $92 \%$, close to the average of $94 \%$ in Drechsler, Savov, and Schnabl (2017). We set the proportional issuance cost parameter, $\psi_{1}$, to 5\% (Boyson, Fahlenbrach, and Stulz, 2016). The fixed cost parameter, $\psi_{0}$, governs how frequently the

\footnotetext{
${ }^{44}$ ROA in the model is state-dependent. When $k$ is large, the bank only holds risky assets (and the asset value is $\left.A_{t}\right)$, but when $k$ is small, the bank also holds risk-free assets $(B<0)$ and the asset value is $A_{t}-B_{t}$.

${ }^{45}$ Sundaresan and Wang (2014) in turn refer to the calculation of Moody's KMV Investor Service.

${ }^{46}$ The following rates are available until Mar. 2021. The average non-jumbo $(<\$ 100,000)$ savings rate is $0.09 \%$. The average non-jumbo 12-month certificate of deposit (CD) rate is $0.38 \%$. The average non-jumbo money market deposit rate is $0.14 \%$. The average non-jumbo checking deposit rate is $0.06 \%$. The average jumbo 12 -month CD rate is $0.40 \%$. The average jumbo money market deposit rate is $0.22 \%$. The sample starts in July 2009 (after GFC).

${ }^{47} \mathrm{Lin}(2019)$ reported a $6 \%$ per quarter (annualized to 12\%) at individual bank level and $1.5 \%$ per quarter (annualized to 3\%) for the banking sector. The values of $\sigma_{X}$ that we consider are between these two values $(0.03$ and 0.12). Idiosyncratic deposit shocks are averaged out in aggregation, so naturally, the sector-level volatility is lower. In practice, the sharing of deposit shocks among banks is often done via the interbank market (Bhattacharya and Gale, 1987). For example, when a depositor sends a payment to another depositor at a different bank, the payer's bank loses deposits while the payee's bank gains deposits. The payee's bank can then lend to the payer's bank in the interbank market. Such arrangements are automatically set up along payment activities in deferred net settlement (DNS).
} 
A: Marginal Value of Equity Capital

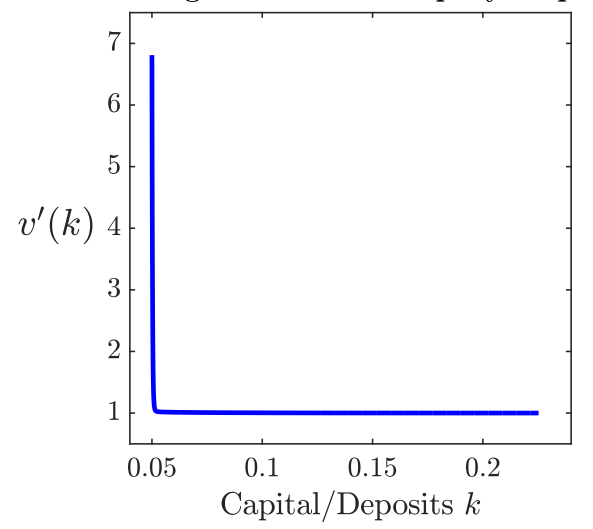

B: Loans/Capital

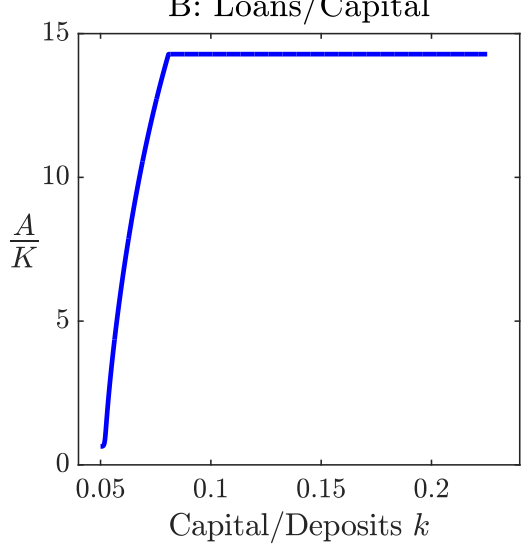

Figure 1: Marginal Value of Equity Capital and Bank Risk-Taking.

bank issues equity. It is set to $0.1 \%$, so that the issuance frequency is once in every four years, in line with the evidence (Baron, 2020). ${ }^{48}$ The regulatory parameters are discussed in Section 2.

\subsection{Marginal Value of Equity Capital and Risk-Taking}

The marginal value of equity capital, $V_{K}(K, M)=v^{\prime}(k)$, should equal one when there are no equity issuance costs because the bank is then indifferent between paying out one dollar and retaining one dollar of earnings. Precautionary savings (i.e., retained earnings) are necessary to reduce reliance on outside equity financing when equity financing is costly. Accordingly, the marginal value of equity capital can be above one in the presence of equity issuance costs, and the wedge between $v^{\prime}(k)$ and one widens as the bank approaches the boundary of equity issuance. Panel A of Figure 1 plots the marginal value of equity capital, $v^{\prime}(k)$, against the equity capital-to-deposit ratio, $k$. At the equity issuance boundary of $k, \underline{k}$, a value of $v^{\prime}(k)$ close to seven dollars means that one dollar of equity is worth seven because of the imminence of costly equity issuance. ${ }^{49}$

The interior region ends at the endogenous payout boundary $\bar{k}$. At that point the marginal value of equity capital is equal to one, and the bank has a sufficient amount of retained earnings, so

\footnotetext{
${ }^{48}$ Baron (2020) calculated the frequency of equity issuance across size groups. The average is once is four years.

${ }^{49}$ The proportional cost is only $5 \%$, but due to the fixed cost, the marginal value of equity is much higher than 1.05 .
} 
that it is optimal to pay out dividends to shareholders given that they discount cash flows at a higher rate $\rho$ than $r$. Note that near the payout boundary, $\bar{k}$, the marginal value of equity capital is close to one and relatively insensitive to variations in $k$ because, at that point, the likelihood of a large loss of equity capital, or a large deposit inflow that markedly pushes $k$ to the equity issuance boundary $\underline{k}$ is low. In other words, distress in the form of costly equity issuance is a distant scenario near $\bar{k}$.

Throughout the whole interior region of $k$, the marginal value of equity capital stays positive, which implies that when the bank accumulates more equity capital, ceteris paribus, the bank's shareholder value increases. This is in line with the evidence in Mehran and Thakor (2011) and Minton, Stulz, and Taboada (2019) that bank value increases with bank capital. In the next subsection, we examine the marginal contribution of deposits to bank shareholder value and discuss further the implications of our model for empirical analyses of bank valuation (Atkeson, d'Avernas, Eisfeldt, and Weill, 2019). Our model also predicts that the bank pays dividends when equity capital is high relative to its deposit liabilities and raises equity when equity capital is low. The procyclical payout and countercyclical equity issuance are consistent with the evidence on bank equity management (Adrian, Boyarchenko, and Shin, 2015; Baron, 2020).

As equation (19) for the optimal loan-to-capital ratio, $A / K$, indicates the marginal value of equity capital directly drives the bank's risk-taking behavior through $\gamma(k)$, the bank's endogenous relative risk aversion defined in (20). Panel A of Figure 1 suggests that $\gamma(k)$ decreases in $k$, because as $k$ increases, the concavity of the bank shareholder value function flattens our quickly and, as $k$ approaches $\bar{k}$ (the payout boundary), this value function is almost linear in $k$ with $v^{\prime}(k)$ close to one. Indeed, in Panel B of Figure 1, we show that the loan-to-capital ratio increases in $k$. The bank cannot exceed the capital requirement (i.e., $A / K \leq \xi_{K}=14.3$ ), but it can expand its balance sheet up to that limit. Our model predicts that risk-taking is procyclical, in line with the evidence that distressed banks reduce risk-taking (Ben-David, Palvia, and Stulz, 2020). In Appendix B, we include jump risk in the asset return. The jump risk makes the increase of $A / K$ in $k$ much smoother as it motivates the bank to be more cautious even as $k$ increases.

An interesting feature of our model is that deposit inflow can decrease bank lending if it is not accompanied by a simultaneous increase in bank equity capital. An increase in $X$ reduces 

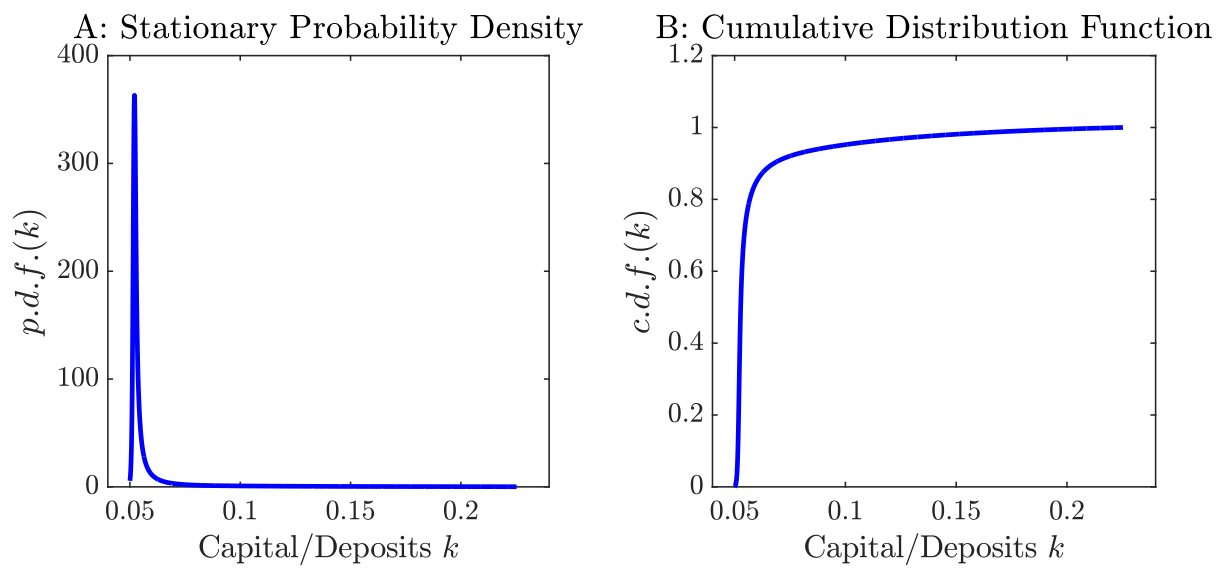

Figure 2: Stationary Probability Density and Cumulative Distribution Function of $k$.

$k=K / X$ and therefore reduces the risk lending-to-equity ratio, $A / K$. If the bank has the same amount of capital, $K$, then the total amount of lending, $A$, declines. This result sheds light on the lack of lending in response to the deposit inflows during the Covid-19 pandemic.

Figure 1 reports the marginal value of equity capital and optimal loan-to-capital ratio for any value of $k$. To understand the long-run behavior of this model (i.e., how much time the bank spends in different regions of $k$ ), we examine the stationary density of $k$. Panel A of Figure 2 plots the stationary probability density of $k$ and Panel B plots the corresponding cumulative distribution function (c.d.f.). While the probability mass is concentrated in the area where $k$ is near the lower boundary $\underline{k}$, the marginal value of equity capital is only slightly above one (1.02) where the density function peaks. However, even if the bank does not seem to be financially constrained for the majority of time, the shadow value of equity rises dramatically when equity is depleted relative to the bank's deposit liabilities and $k$ approaches $\underline{k}$, as shown in Panel A of Figure 1. These results illustrate the sharp contrast between normal times, when the bank is comfortably meeting its leverage requirements, and crisis times, when it is in danger of violating the leverage requirement and triggering equity issuance.

In Panel A of Figure 3, we plot the marginal value of equity capital against the stationary c.d.f. of $k$ (note c.d.f. $(\underline{k})=0$ and c.d.f. $(\bar{k})=1$ ). An interval on the horizontal axis in this figure represents the fraction of time that the bank spends in the corresponding region of $v^{\prime}(k)$ on 

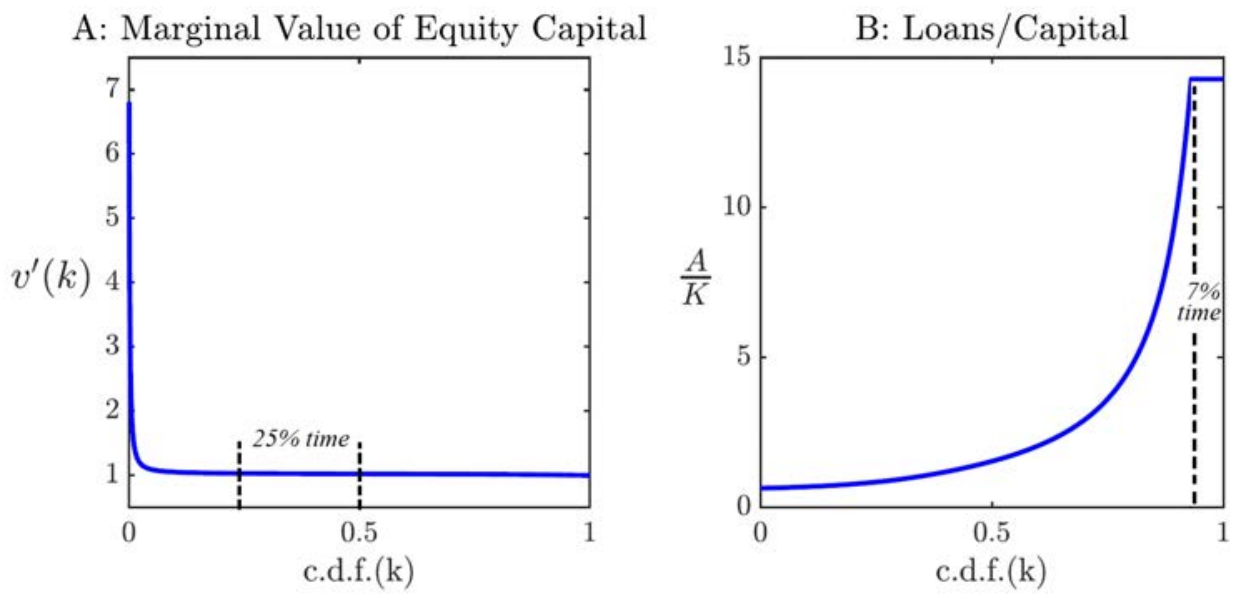

Figure 3: Long Run Distribution of Marginal Value of Equity Capital and Loan-Capital Ratio.

the vertical axis. For example, the bank spends $25 \%$ of the time with its marginal value of equity between 1.022 and 1.029. The bank spends less than $5.5 \%$ of the time in the region where it is in danger of violating the leverage requirement with $v^{\prime}(k)$ above 1.08. In other words, crisis states are rare, but they cast a long shadow over the bank's management of its balance sheet.

In Panel $\mathrm{B}$ of Figure 3, we plot the optimal loan-to-capital ratio, $A / K$, against the stationary c.d.f. of $k$. We show that capital requirements bind about $7 \%$ of the time (the horizontal part of the curve on the right end). The capital requirement becomes relevant when the bank is well-capitalized and the risk-taking incentive is strong. Such procyclicality suggests that capital requirements can act as a macroprudential tool as in Gersbach and Rochet (2017). In contrast, the SLR requirement motivates the bank to replenish equity capital in bad times, when its equity capital is low relative to its deposit liabilities. While the capital requirement and leverage regulation play distinct roles in our model, they both contribute to a form of parity between risk and capital with the former restricting risk-taking given equity capital and the latter triggering capital raising.

\subsection{Deposit marginal $q$}

Bank shareholder value depends on equity capital, $K$, and deposits, $X$. Panel A of Figure 4 plots the marginal value of deposits (the deposit marginal $q$ ), $V_{X}(X, K)=v(k)-v^{\prime}(k) k$. When the 

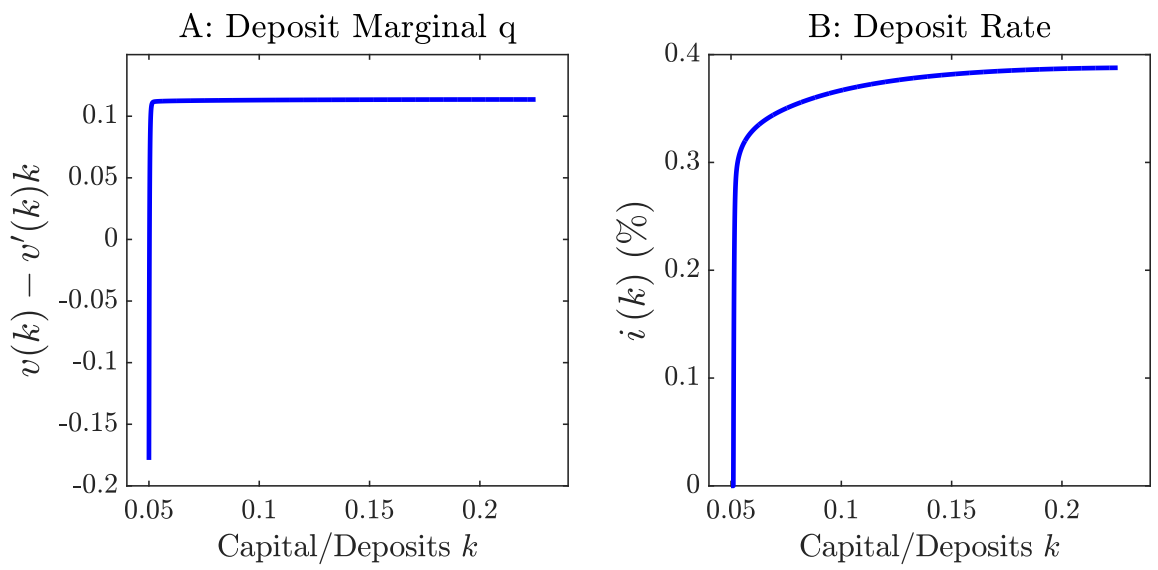

Figure 4: Deposit marginal $q$ and Deposit Rate.

bank has ample capital relative to deposits (when $k$ is large), the deposit marginal $q$ is positive. However, it turns sharply negative when $k$ is near the lower boundary of costly equity issuance.

Deposits create value as they are a cheaper source of funds than wholesale funding (shortterm bonds) or equity. Intuitively, when the bank becomes better capitalized, it raises the deposit rate to attract deposits for more risky lending. Panel B of Figure 4 shows that the deposit rate increases in $k$, as the loan-to-equity ratio does in Panel $\mathrm{B}$ of Figure $1 .^{50}$ When the bank becomes undercapitalized ( $k$ decreases), it reduces the deposit rate in order to deleverage. Li and Li (2021) provide evidence on the positive correlation between bank capital and the deposit rate. Acharya and Mora (2015) found that undercapitalized banks tend to raise deposit rates, but their focus is on distressed banks that have to pay a higher default risk premium to depositors as they become more undercapitalized. In our model, the bank never becomes insolvent under the regulatory constraints, so the depositors do not demand a default risk premium.

A key finding in Figure 4 is that the deposit marginal $q$ declines sharply and turns negative when the bank's equity capital is low relative to its deposit liabilities. ${ }^{51}$ When $k$ is near the equity issuance boundary, $\underline{k}$, deposit inflows make costly equity issuance more likely by further reducing

\footnotetext{
${ }^{50}$ The positive comovement of loan growth and deposit rate increase is consistent with the findings in Ben-David, Palvia, and Spatt (2017).

${ }^{51}$ In Appendix B, we show that the jump risk in bank asset return makes the dynamics of deposit marginal $q$ and deposit rate smoother near the equity issuance (lower) boundary of $k$.
} 

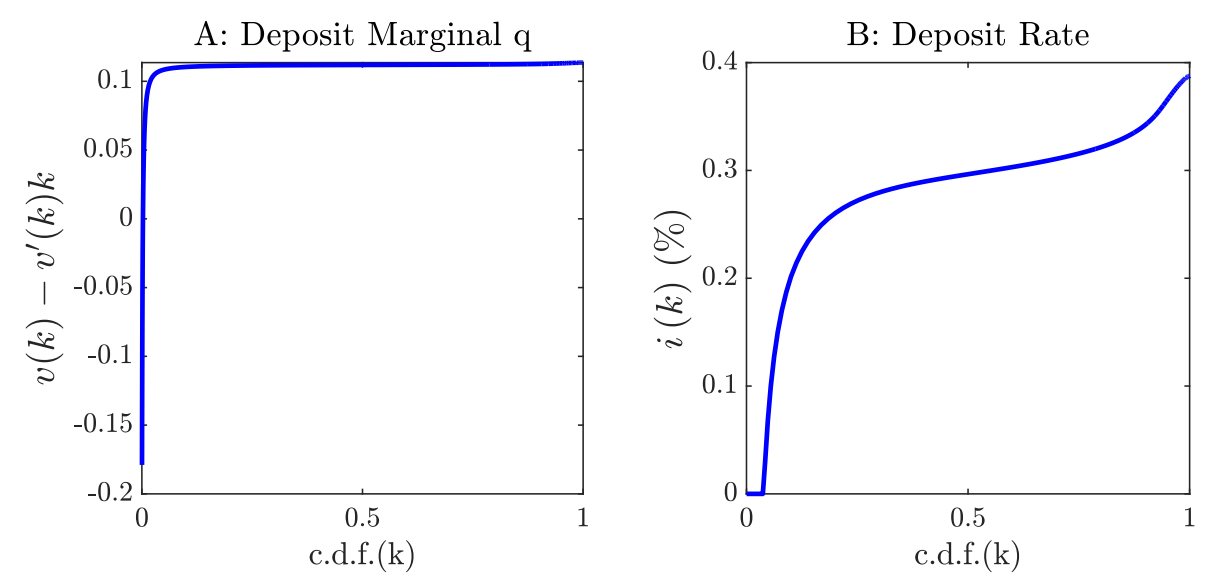

Figure 5: Long Run Distribution of Deposit Marginal $q$ and Deposit Rate.

$k=K / X$. The bank may then want to delever, turning away deposits by lowering the deposit rate. However, as shown in Panel B of Figure 4, doing so has a limit, the zero lower bound (ZLB) for the deposit rate. In Section 6.1, we relax the ZLB constraint and show that our results are robust.

In Figure 5, we plot the deposit marginal $q$ and optimal deposit rate against the stationary c.d.f. of $k$. The deposit marginal $q$ is positive and larger than $0.1180 \%$ of the time, but near the lower boundary of costly equity issuance, it can drop to -0.18 . The deposit rate hovers around the lower bound at zero, showing that the bank is very conservative in deposit-taking. As we have already mentioned, deposits differ from short-term debt. The bank can continuously and freely adjust its short-term debt level, and therefore, does not face a problem of unwanted debt. This is not true for deposits. Deposits leave the bank only when depositors choose to withdraw their money, or when they make payments to depositors at other banks. If depositors are willing to hold deposits, the bank cannot turn them away. The bank must also accept any deposit inflow unconditionally. For example, when a depositor receives payroll deposits. After hitting the zero lower bound, the bank no longer has any instruments to reduce deposits and thus loses control of its leverage. Therefore, when the bank is sufficiently close to the costly equity issuance boundary (near $\underline{k}$ ) the marginal value of deposits turns negative.

Figure 6 analyzes the bank's debt structure. Panel A plots the ratio of short-term debt to deposits, $B / X$, against $k$ and Panel B plots this ratio against the stationary c.d.f. of $k$ to show 

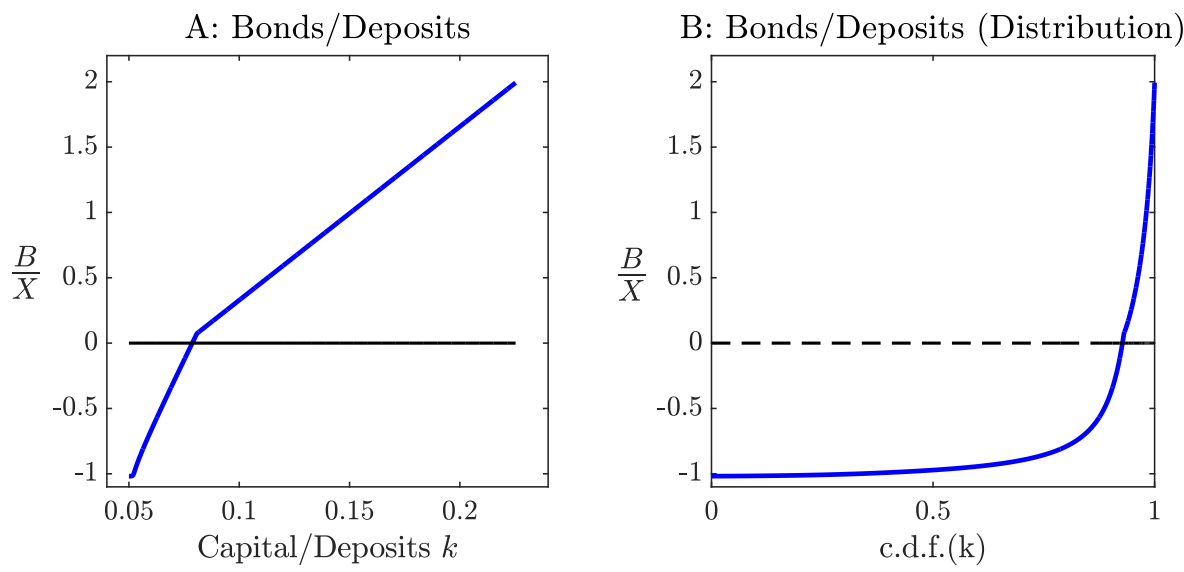

Figure 6: Bank Debt Structure.

how much time the bank spends in different regions of $B / X$. When capital is abundant relative to deposits, the bank raises funds through wholesale funding (short-term debt, $B>0$ when $k$ is high) to expand its balance sheet. As $k$ increases, the bank becomes increasingly reliant on wholesale funding instead of deposits. The substitution from deposits to wholesale funding reflects the bank's preference for more controllable short-term debt despite its higher interest costs (in our solution, the deposit rate is below the risk-free rate $r$ of $1 \%$; see Panel B of Figure 4).

Panel A of Figure 6 also shows that when the bank's equity is low relative to its deposit liabilities, the bank holds risk-free bonds ( $B<0$ when $k$ is low) to reduce the overall riskiness of its asset portfolio. The bank manages its exposure to both asset-return risk and deposit risk to avoid incurring the equity issuance costs. When $k$ declines, the optimal deposit rate approaches the lower bound. Once the deposit rate hits the lower bound, the bank loses control of its deposit liabilities and can no longer manage deposit risk. Instead, the bank focuses on reducing its exposure to assetreturn risk, and doing so requires holding safe assets. ${ }^{52}$ This new channel of safe asset demand is strong when banks are undercapitalized and close to breaching the leverage requirement.

\footnotetext{
${ }^{52}$ Empirically, we often observe banks holding safe assets and simultaneously issuing short-term debts. In Appendix A, we follow Drechsler, Savov, and Schnabl (2018) to incorporate the bank's need to hold reserves and other liquid assets under payment settlement frictions (Furfine, 2000; Bech and Garratt, 2003; Ashcraft, McAndrews, and Skeie, 2011; Bianchi and Bigio, 2014). This additional feature distinguishes safe assets and the bank's own short-term debts.
} 


\section{Applications}

In this section, we use our model as a laboratory to analyze implications for leverage regulation (Subsection 5.1) and challenges that banks face in a low interest-rate environment (Subsection 5.2).

\subsection{Leverage Regulation}

Overview. U.S. banking regulators relaxed the SLR requirement in response to the crisis provoked by the Covid-19 pandemic. Jerome Powell, the Federal Reserve Chairman, emphasized that the SLR is straining banks' ability to handle large deposit inflows. "Many, many bank regulators around the world have given leverage ratio relief," Powell said at a news conference following an FOMC meeting. "What it's doing is allowing [banks] to grow their balance sheet in a way that serves their customers." 53 To shed light on this decision, we examine the effects of relaxing the SLR requirement on bank balance-sheet management and valuation.

Relaxing the SLR increases the deposit marginal $q$, helping the bank to absorb deposit inflows. However, if the deposit inflow persists, the deposit marginal $q$ could fall even below the level prior to the relaxation of SLR. Relaxing the SLR also stimulates lending in the short run by reducing the likelihood of costly equity issuance and thus boosting the bank's risk-taking capacity. However, contrary to conventional wisdom, it leads to less risk-taking over the long run. Tightening the SLR has the opposite effect: It discourages the bank from risk-taking in the short run but, over the long run, the bank becomes more aggressive in taking risk. The key to these results is that equity issuance costs generate a reach-for-yield incentive. To compensate shareholders for more frequently incurred issuance costs under a tighter SLR requirement, the bank needs to raise its return on equity over the long run. Next, we provide more detailed analysis.

Lending and risk taking. The bank must raise equity and incur issuance costs to stay in compliance with the leverage requirement when it hits the lower bound $k$. Relaxing the SLR lowers $\underline{k}$, so that costly equity issuance becomes a more distant event. A lower likelihood of paying equity

\footnotetext{
${ }^{53}$ See "Fed's Powell makes case why Congress should relax bank capital rule" by Hannah Lang, American Banker July 29, 2020. The SLR requirement also affected the functioning of Treasury market (He, Nagel, and Song, 2021).
} 

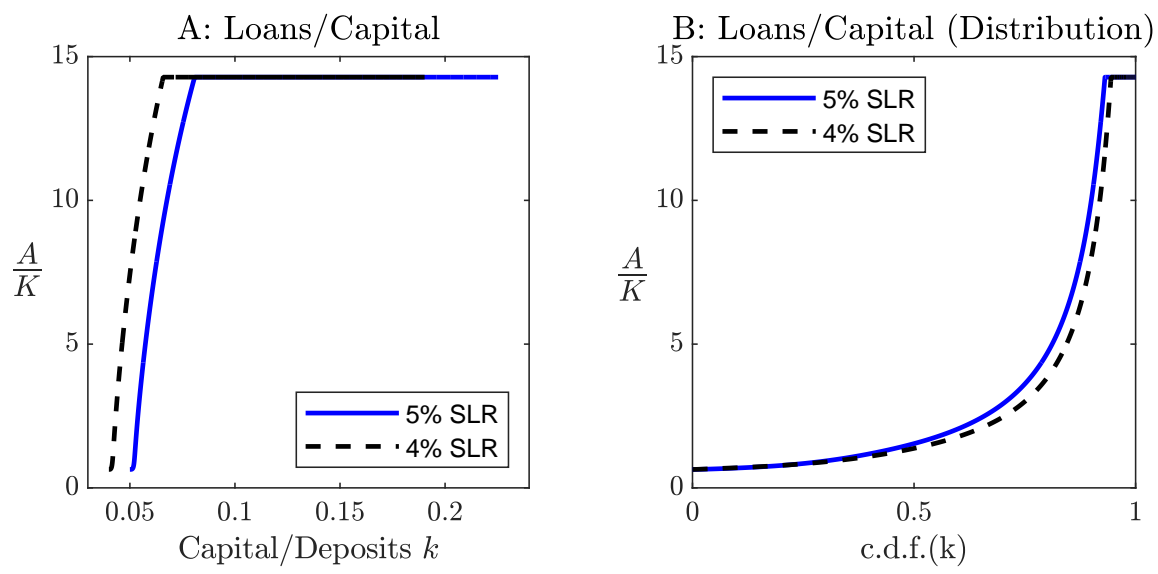

Figure 7: The Impact of Relaxing the SLR Requirement on Bank Lending.

issuance costs makes the bank less risk-averse and thereby stimulates lending as shown in Panel A of Figure 7, where we compare the loan-to-equity capital ratio, $A / K$, under respectively an SLR requirement of $5 \%$ and $4 \%$ (the dashed line). As can be seen, $A / K$ is higher under a lower SLR. In both cases, $A / K$ peaks at the level given by the risk-based capital requirement.

Many commentators have raised concerns that relaxing leverage regulations will cause the bank to take on more risks over the long run. ${ }^{54}$ Consistent with this intuition, Panel A of Figure 7 shows that the payout and equity issuance boundaries both shift leftward after the regulatory change: Relaxing the SLR requirement makes the bank less risk-averse and maintain less equity (relative to deposit liabilities). However, this does not necessarily imply a higher risk exposure per unit of equity capital over the long run as shown in Panel B. Drawing the distinction between Panels A and B is important for understanding our model predictions on banks' risky lending. Panel A shows the impact of relaxing the SLR requirement given $k$, which summarizes the current state of the bank's balance sheet. The move from the solid line to the dashed line mimics the immediate effect of the regulatory change. In contrast, Panel B shows the long-run effect. The plot of $A / K$ against the stationary c.d.f. of the state variable $k$ shows how much time the bank

\footnotetext{
${ }^{54}$ When discussing the relaxation of SLR requirement, Fed chairman Powell emphasized that "This will not be a permanent change in capital standards." (see "Fed's Powell makes case why Congress should relax bank capital rule" by Hannah Lang, American Banker July 29, 2020).
} 
spends (horizontal axis) at different levels of risky lending per unit of capital, $A / K$ (vertical axis). Contrary to conventional wisdom, relaxing the SLR actually leads to a smaller risk exposure per unit of equity capital over the long run as the dashed line is below the solid line in Panel B.

Similarly, tightening leverage regulations can actually lead to more aggressive risk-taking over the long run, as it implies more frequent costly equity issuance. The bank must engage in more risk-taking per unit of equity to generate earnings (return on equity) that offset issuance costs. Equity issuance costs generate a reach-for-yield incentive (Li, 2019). ${ }^{55}$ Tightening the SLR achieves the purpose of incentivizing the bank to maintain more equity over the long run, yet it fails to tame risk-taking. Our mechanism captures bankers' focus on return on equity in practice.

In 2021, U.S. bank regulators restored the SLR requirement to the pre-pandemic level. Through the lens of our model, this policy change incentivizes banks to expand risky lending over the long run but to scale back risky lending in the short run. From an impulse response perspective, our model predicts that banks' incentive to lend declines immediately, then rises over time, and eventually settles at a higher level. Therefore, the impact of this policy change on the economic recovery depends on how fast the demand for bank credit rebounds. If credit demand recovers slowly, the response of banks' credit supply may very well match the demand. However, if credit demand rebounds sharply, then the response of bank credit supply may lag the rise in demand and slow down the overall economic recovery.

When $k$ is low and $B<0$, the lower (equity issuance) bound for $k$ is given by the SLR requirement. When $k$ is high and $B>0$, the SLR requirement imposes a restriction on the loan-toequity capital ratio (see (8)), just as the risk-based capital requirement does (see (7)). Under current regulatory parameter values, the capital requirement binds before the SLR when $k$ is high, so that in our model, the two regulations play distinct roles: The SLR pins down the lowest amount of equity capital relative to deposits and the capital requirement restricts the risk exposure per unit of equity capital. Hence, in our model risk-based capital requirements have a more direct effect in taming risk-taking than the SLR. ${ }^{56}$ However, this conclusion relies on an important assumption that the

\footnotetext{
${ }^{55} \mathrm{Li}$ (2019) presents a model of financial instability induced by government debt where the supply of governmentissued money-like securities (e.g., Treasury bills) squeezes banks' profits from issuing money-like securities, so banks become more aggressive in risk-taking to sustain earnings that can offset the costs of issuing equity over the long run.

${ }^{56}$ The SLR is more effective in triggering equity issuance. In our model, an undercapitalized bank can freely adjust
} 
A: Deposit Marginal q

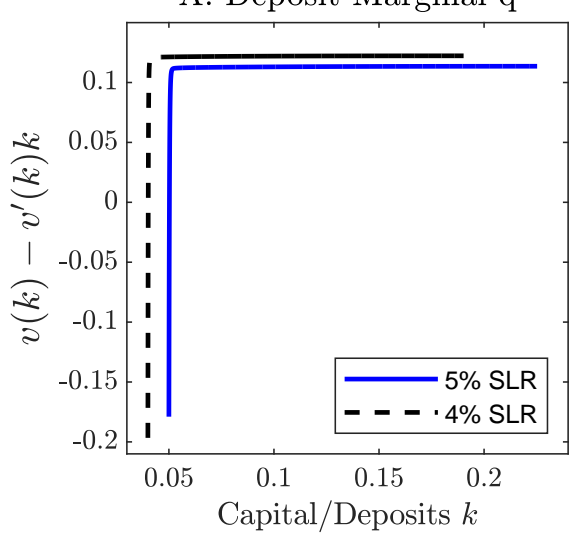

B: Deposit Rate

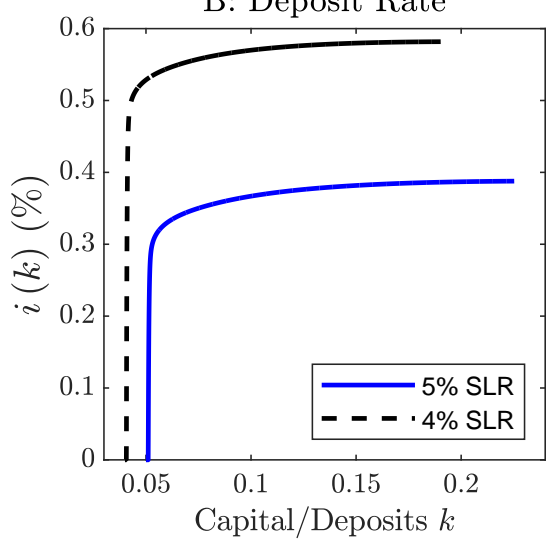

Figure 8: Impact of Relaxing the SLR Requirement on Deposit Taking.

riskiness of loans (given by the parameter $\sigma_{A}$ ) is time-invariant. When loan risk is countercyclical, risk-based capital requirements amplify the procyclicality of bank risk-taking (Repullo and Suarez, 2012). Moreover, risk weights are vulnerable to manipulation (Plosser and Santos, 2014). Because our model is designed to focus on deposit risk and the bank's imperfect control of balance-sheet size and composition, we do not include the possibility of equilibrium bank failures in our model and the associated externalities that motivate both the leverage and risk-based capital requirements. Therefore, our analysis does not aim to provide a comprehensive evaluation of banking regulations.

Deposit taking. One motivation for relaxing the SLR during the Covid-19 pandemic was to allow banks to accommodate the unprecedented deposit inflows without concerns over violating regulatory constraints. In Panel A of Figure 8, we plot the marginal value of deposits, $V_{X}(X, K)=$ $v(k)-v^{\prime}(k) k$, before (solid line) and after (dashed line) the SLR requirement is reduced. To see the model predictions, pick any value of $k$ on the solid line and consider the vertical movement to the dashed line. This mimics the immediate response of a bank to the regulatory change given its balance sheet (the value of $k$ ). The regulatory change achieves its intended purpose of stimulating

downward $A_{t}$ at any time $t$, so the capital requirement does not trigger equity issuance. The adjustment of loan portfolio has become easier over time. Technological progress on the reduction of information asymmetries facilitates loan trading. The design of contract between loan buyers and originators alleviates the moral hazard (reduced monitoring incentive) on the part of loan originators (Pennacchi, 1988; Gorton and Pennacchi, 1995). 
deposit-taking as the deposit marginal $q$ jumps up. The jump is most significant for low values of $k$ where the deposit margin q turns negative before the regulatory change.

If the deposit inflow persists after the regulatory change, raising deposits, $X$, and reducing $k=K / X$, the bank moves along the dashed line to the left in Panel A of Figure 8 and its deposit marginal $q$ declines. Note that after the SLR is relaxed, the deposit marginal $q$ turns even more negative near the new lower equity issuance boundary. This is because equity capital is now lower relative to deposits at the new issuance boundary so that the effects of deposit inflows on $k$ (= $K / X)$ are greater. Once the deposit inflow pushes the deposit marginal $q$ into the negative territory, further relaxing the SLR becomes necessary to stimulate deposit-taking.

We plot the deposit rate in Panel B of Figure 8. After the SLR requirement is reduced, the bank increases the deposit rate to attract deposits because the deposit marginal $q$ is higher. As a result, the region of $k$ where the deposit-rate lower bound binds, shrinks significantly. By the same logic, tightening leverage regulation has the unintended consequence of making the lower bound more likely to bind, so that the bank has less control over the size and composition of its balance sheet. This unintended consequence of leverage regulation is a unique prediction of our model.

\subsection{Banking in a Low Interest Rate Environment}

The bank expects to earn a net interest margin (NIM) when it finances lending with deposits. The spread between the expected loan return, $r+\alpha_{A}$, and the deposit rate, $i$, is positive. To earn a positive NIM the bank takes on asset-return risk and/or deposit flow risk. We decompose the net interest margin into two components, $\alpha_{A}$ from lending expertise and the deposit spread, $(r-i){ }^{57}$ The bank suffers in a low interest rate environment, because a low $r$ squeezes the deposit spread and makes the deposit-rate lower bound a more binding constraint. In our model, the NIM is not only a measure of profitability as in traditional banking models, but, more importantly, the NIM reflects the bank's flexibility in managing its deposit liabilities.

\footnotetext{
${ }^{57}$ The deposit spread reflects the bank's deposit market power (Drechsler, Savov, and Schnabl, 2017) and the extent to which depositors value the convenience of deposit accounts for payment activities. Motivated by the role of deposits as means of payment, the deposit spread is also called money premium (Stein, 2012; DeAngelo and Stulz, 2015; Krishnamurthy and Vissing-Jørgensen, 2015; Greenwood, Hanson, and Stein, 2015; Li, 2019; Begenau, 2020).
} 

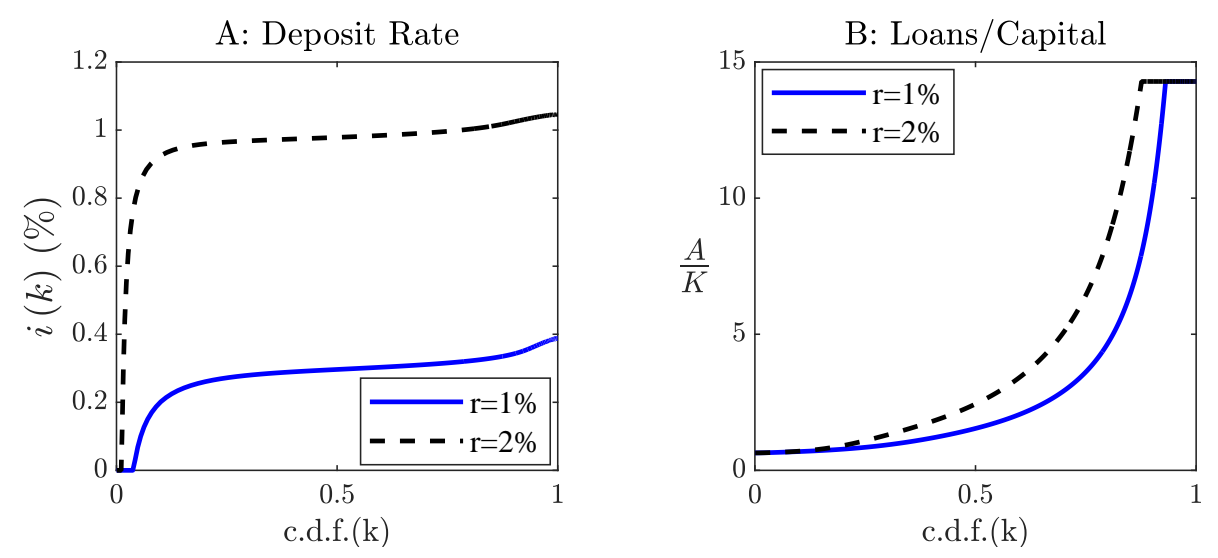

Figure 9: Interest Rate Level, Deposit Rate, and Lending.

As shown previously, the bank increases its deposit rate when it is well-capitalized (i.e., $k$ is high). Given the deposit rate lower bound, the higher the bank can set its deposit rate in the high- $k$ region, the more flexibility it has in reducing its deposit rate when $k$ declines. However, raising the deposit rate increases interest expenses and hurts earnings. Therefore, the bank faces a trade-off. It can sacrifice its earnings in the high- $k$ region to gain flexibility in adjusting the deposit rate in the low- $k$ region. When the risk-free rate $r$ is high, the bank can set a high deposit rate and still earn a positive deposit spread $r-i$. When the risk-free rate $r$ is low, the bank has less room to manipulate the deposit rate without squeezing the deposit spread too much.

Therefore, the flexibility to adjust the deposit rate and to control deposit flows depends on the distance between $r$ and zero, the deposit-rate lower bound. When $r$ is high, the bank has more flexibility in setting its deposit rate and thus is more in control of the size of its deposit liabilities. In contrast, the bank in a low-rate environment faces a greater challenge of managing its deposit liabilities. This mechanism is consistent with the empirical findings. For example, Heider, Saidi, and Schepens (2019) find that the distribution of deposit rates of euro-area banks is truncated at zero and more deposit rates bunch at zero once the ECB lowers the policy rate.

In Figure 9, we report comparative statics for $r$. We consider $r=1 \%$ (the baseline case) and $r=2 \%$. As $r$ increases from $1 \%$ to $2 \%$, we allow the bank's time-discount rate $\rho$ to increase by $1 \%$ as well so that we control for the wedge between $\rho$ and $r$. Panel A plots the deposit rate against 
the c.d.f. of $k$, so that the $\mathrm{x}$-axis provides information on the fraction of time that the deposit rate spends in different regions (the y-axis). In Panel B, we report the other key decision variable related to bank lending, the loan-to-equity capital ratio, $A / K$.

In Panel A of Figure 9, the bank sets a higher deposit rate when $r$ is higher. However, the transmission of variation in $r$ to the deposit rate is imperfect as in Drechsler, Savov, and Schnabl (2017) and Wang (2018). The deposit rate under $r=2 \%$ is less than $0.8 \%$ (rather than $1 \%$ ) higher than the deposit rate under $r=1 \%$. Under a higher $r$, the bank enjoys a higher deposit spread, $r-i$. A higher risk-free rate also offers the bank more flexibility to manage such risk. As shown in Panel A of Figure 9, when $r$ is higher, the bank is more aggressive in raising the deposit rate in the high- $k$ region to preserve more flexibility for anticipated rate reductions when $k$ declines. As can be seen, the zero lower bound for $i$ becomes less binding under $r=2 \%$ than under $r=1 \%$.

In Panel B of Figure 9, we show that the bank reduces its lending per unit of equity capital, $A / K$, when $r$ declines from $2 \%$ to $1 \%$. In other words, under a lower interest rate, the bank reduces lending. This seemingly counterintuitive result has a straightforward explanation: Under a lower $r$, the bank has less flexibility in managing deposit risk, so it becomes more conservative in taking lending risk in order to maintain an overall balanced risk profile. This result sheds light on the transmission of monetary policy and adds to the recent debate on why lowering the policy rate does not simulate bank lending (e.g., Repullo, 2020; Brunnermeier, Abadi, and Koby, 2023).

\section{Extension and Robustness}

We first generalize our model to allow for a negative deposit rate in Subsection 6.1. In Subsection 6.2 , we modify our baseline model to allow the bank to pay a cost to reduce deposits.

\subsection{Negative Deposit Rate}

In this section, we relax the zero lower bound on the deposit rate, $i_{t}$. As we have argued above, when the bank is undercapitalized and over levered, it may want to set a negative deposit rate to turn away deposits. However, setting a negative deposit rate is such a salient move that it may 
induce depositors to withdraw deposits in large numbers. To characterize this scenario, we assume that once the bank sets $i_{t}<0$, it faces the risk of a Poisson-arriving large withdrawal of deposits. We denote the Poisson arrival rate by $\lambda_{D}\left(i_{t}\right)$ and assume that it is decreasing in $i_{t}$, so that the further below zero $i_{t}$ is, the more likely is a massive withdrawal event. When the Poisson shock hits, the bank's deposits decline from $X_{t-}$ to $X_{t}=X_{t-}\left(1-\Delta_{X}\right)$, where $\Delta_{X}$ is the fraction of deposit loss drawn from a probability distribution on $[0,1]$. To meet such large withdrawals, the bank must sell its assets and incur a liquidation cost of $\eta_{L} \Delta_{X} X_{t-}$ that is proportional to the withdrawn amount. ${ }^{58}$ Therefore, the bank faces a trade-off between turning away unwanted deposits and facing the consequence of entering into an uncharted territory of large random deposit withdrawals triggered by the salient negative rate. The impact of such withdrawal risk can be seen from the value function, $V(X, K)$. On the one hand, a decline in $X$ benefits the bank as the marginal value of deposits, $V_{X}(X, K)$, is negative when the bank sets $i_{t}<0$; on the other hand, the liquidation cost reduces bank equity capital, $K$, which has a positive marginal value, $V_{K}(X, K)$.

In Figure 10, we plot the solution of this extension. For each level of $k$, we report the values of two key control variables, deposit rate and the risky asset-to-capital ratio, $A / K$, in Panels $\mathrm{A}$ and $\mathrm{B}$, respectively, and the marginal values of deposits and equity in Panels $\mathrm{C}$ and $\mathrm{D}$, respectively. The derivation details are provided in Appendix C. The parameters are chosen so that the extension generates similar dynamics as the baseline model with a zero lower bound (ZLB) and therefore offers a theoretical foundation for the ZLB. Specifically, we assume that $\Delta_{X}$ is drawn from a uniform distribution on $[0,1]$ and specify the intensity function $\lambda_{D}(i)=\zeta_{D}\left(e^{-i}+i-1\right)$ with $\zeta_{D}=10,000$ for $i<0$ and $\lambda_{D}(i)=0$ for $i \geq 0$. The functional form is chosen so that it smoothly pastes to a zero at $i=0$ (i.e., $\lambda_{D}(0)=0$ and $\lambda_{D}^{\prime}(0)=0$ ). Under a negative deposit rate of $-0.5 \%$, the arrival rate results in around a once in fifteen years event. The percentage cost of liquidation, $\eta_{L}$, is $5 \%$. Even under these conservative parameters, the model still generates a strong incentive to avoid setting a negative deposit rate. The solution closely mimics that of the baseline model. The bank sets a negative deposit rate, only when $k$ is close to $\underline{k}$ where the deposit marginal $q$ is very negative and the marginal value of equity is high, as costly equity issuance is imminent.

\footnotetext{
${ }^{58}$ Unlike the normal-time continuous adjustment of bank assets, the Poisson time large adjustment is costly.
} 

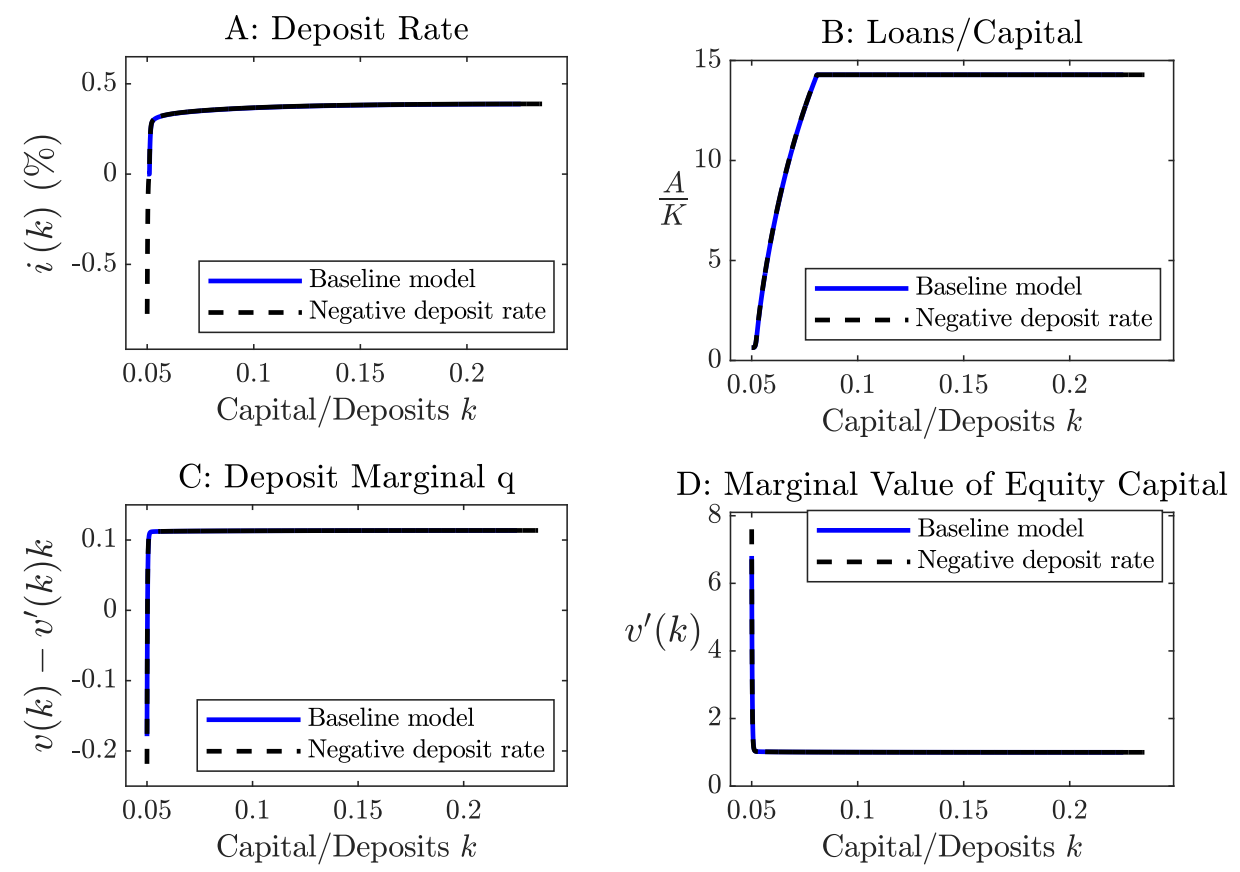

Figure 10: Negative Deposit Rate.

\subsection{Reducing Deposits}

In practice, banks can also turn away deposits by persuading depositors to move money to other banks or to money market funds. These were the options actively pursued by banks in response to the increase in deposits during the Covid-19 pandemic. ${ }^{59}$ Actively pursuing options to reduce deposits suggests a negative deposit marginal $q$. In this subsection, we consider a variant of our model where, instead of raising equity, the bank reduces deposits to increase $k$ in compliance with the leverage requirement. ${ }^{60}$ Reducing deposits by a fraction of $\Gamma_{X} \in[0,1]$ incurs total costs $\psi_{0}^{D} X+\psi_{1}^{D} \Gamma_{X} X$ with a fixed cost scaled by the size of deposit stock, $X$, and a proportional costs.

The costs of reducing deposits capture the bank's efforts to persuade depositors to move money away and the potential negative implications on the bank's brand recognition or customer capital. ${ }^{61}$ Moreover, when funds move out of the deposit accounts, the bank needs to sell assets to

\footnotetext{
${ }^{59}$ See "Banks to Companies: No More Deposits, Please" by Nina Trentmann, Wall Street Journal June 9, 2021.

${ }^{60}$ We effectively assume that the cost of raising equity is higher than that of reducing deposits.

${ }^{61}$ One may think that if money moves to money market funds managed by the same bank, the customer base is not
} 

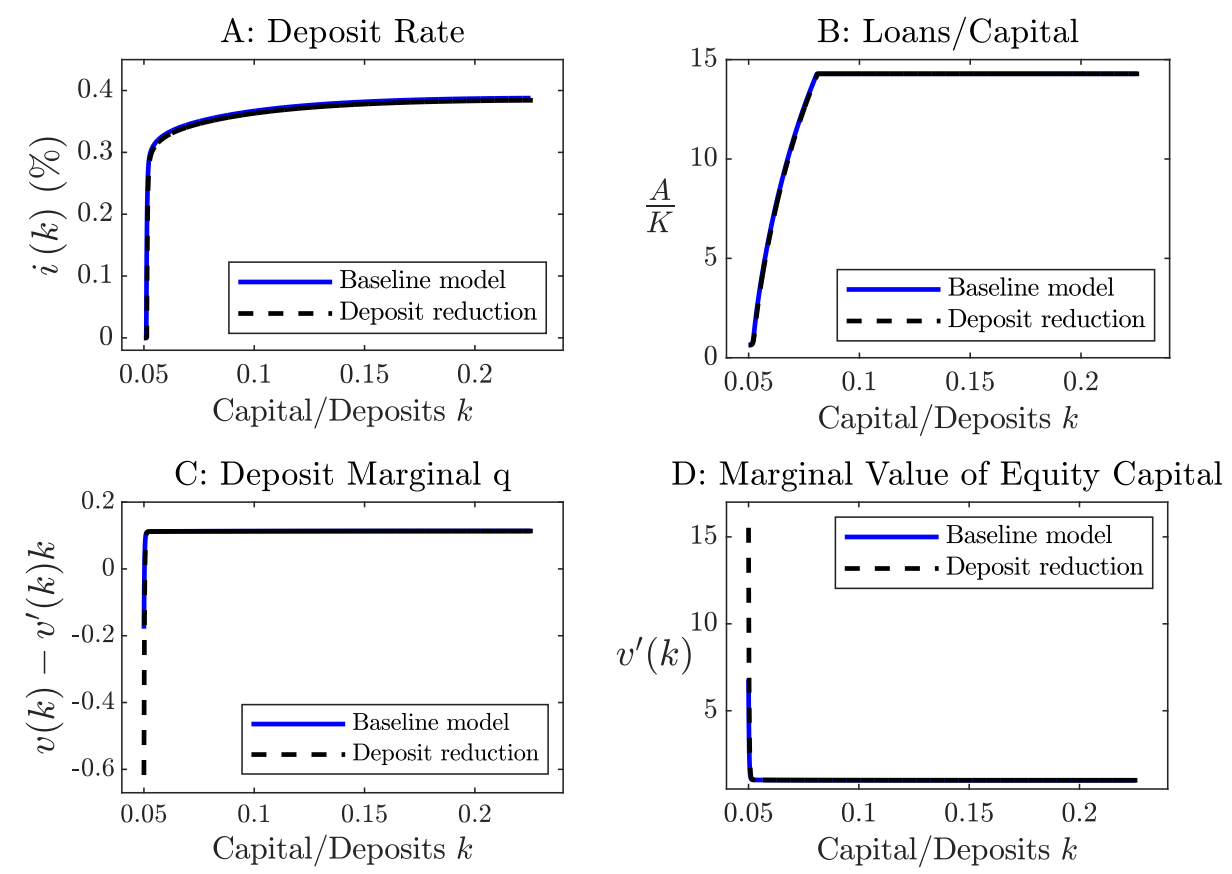

Figure 11: Costly Deposit Reduction.

meet the withdrawal, the associated costs of which are also incorporated into the cost of reducing deposits. The costs of reducing deposits can also be motivated by the regulatory response during the deposit inflows in the Covid-19 episode. If banks can costlessly turn away unwanted deposits, US regulators would not have found it necessary to relax the SLR. When the problem of deposit inflows was acute, regulators traded off the benefits of leverage regulation against the difficulties banks were facing in dealing with large deposit inflows, and they decided to to relax the leverage regulation. In April 2021, the regulators faced a different trade-off and restored the SLR.

Relying on deposit reduction rather than equity issuance to increase $k$ results in a different set of boundary conditions, but the interior dynamics are characterized by the same HJB equation and optimality conditions for optimal choices of $\pi^{A}$ and $i$ as in the baseline model. In analogy to

lost. However, as pointed out by Drechsler, Savov, and Schnabl (2017), banks enjoy deposit market power and earn a spread between the interest rates paid to depositors and the prevailing money market rate. In contrast, money market funds pay the market rate, and banks can only earn the management fees. 
(16) and (15), the value-matching and smooth-pasting conditions are now respectively,

$$
v\left(\frac{\underline{k}}{1-\Gamma_{X}}\right)\left(1-\Gamma_{X}\right)-v(\underline{k})=\psi_{0}^{D}+\psi_{1}^{D} \Gamma_{X},
$$

and

$$
v\left(\frac{\underline{k}}{1-\Gamma_{X}}\right)-v^{\prime}\left(\frac{\underline{k}}{1-\Gamma_{X}}\right) \frac{\underline{k}}{\left(1-\Gamma_{X}\right)}=-\psi_{1}^{D} .
$$

The smooth-pasting condition suggests that at $k=\underline{k} /\left(1-\Gamma_{X}\right)$ (the value after deposit reduction) the marginal value of deposits is negative and equals $-\psi_{1}^{D}$. Reducing deposits is costly so the bank will only do it when there is a benefit (i.e., when the marginal value of deposits is negative).

In Figure 11, we report the values of the two key control variables, the deposit rate and the risky asset-to-capital ratio in Panels A and B respectively, and the marginal values of deposits and equity in Panels C and D respectively. The cost parameters, $\psi_{0}^{D}$ and $\psi_{1}^{D}$, are set to $0.2 \%$ and $0.5 \%$, so that the solution resembles that of the baseline model, and therefore, this alternative setup offers another theoretical underpinning behind the dynamics in our baseline model. As shown in Figure 11, the bank pursues similar strategies in deposit rate setting and risky lending (in Panels A and B respectively) while the impact of the new boundary conditions is limited to the deposit marginal $q$ and the marginal value of equity, which become more extreme near the lower bound.

\section{Conclusion}

Deposit-taking is a double-edged sword. It provides relatively cheap funds but exposes the bank to deposit-flow risk. The bank's inability to fully control its liabilities makes bank balance-sheet management conceptually very different from that of non-depository intermediaries and nonfinancial firms. Under equity issuance costs, the deposit marginal $q$ turns sharply negative for undercapitalized banks. Deposit inflows hurt bank shareholders and lead to less lending. Our model delivers a rich set of predictions on bank lending, payout to shareholders, equity issuance, the choice of leverage through deposit-taking and wholesale funding. It also sheds light on recent developments surrounding the SLR requirement and the challenges banks face in a low interest-rate environment. 
The recent banking turmoil and the failure of Silicon Valley Bank (SVB) further illustrate the importance of deposit risk management. SVB was flooded with deposits (around $\$ 130$ billions new deposits in 2020 and 2021) from startups that had accumulated cash during the Covid-19 shutdown. SVB invested such inflow of deposits in long-term bonds, thereby exposing itself to interest-rate risk. $^{62}$ The episode suggests two interesting directions for future research. One is to introduce interest-rate risk by allowing the bank to hold long-term debt. Another is to generate both a sharp decrease in deposit marginal $q$ in response to large inflows and a sharp increase in response to large outflows. The key to generating a sharp increase in deposit marginal $q$ following outflows is to make loan illiquid so that, as in Bolton, Chen, and Wang (2011), liquidity management becomes important, and large deposit outflows can be costly by draining liquidity (reserves and other liquid assets). A new state variable, the ratio of liquid assets to deposits, naturally emerges. The bank then cares not only about its liability composition (deposits vs. equity) but also about its asset composition between illiquid loans and liquid assets. This means that a more complex analysis is then required involving a partial differential equation for the value function.

Another interesting direction for future research is to incorporate our mechanism in macroeconomic models of safe asset demand (Caballero, Farhi, and Gourinchas, 2008; Gourinchas and Rey, 2016; Maggiori, 2017; Bolton, Santos, and Scheinkman, 2018; He, Krishnamurthy, and Milbradt, 2019; Brunnermeier, Merkel, and Sannikov, 2020). The bank loses control of its leverage once it hits the deposit rate lower bound, so that it holds risk-free bonds to reduce the risk exposure of equity capital. The government is in a unique position to supply safe assets. In a general equilibrium setting where the interest rate $r$ is endogenous, banks' demand is likely to push down $r$. The government can take advantage of a lower borrowing cost, issuing debts and using the proceeds to stimulate the economy. Supplying safe assets is also essential for sustaining $r$ at a sufficiently high level so that banks have enough flexibility in adjusting their deposit rate between zero and $r$. Finally, government debts as deposit substitutes can absorb part of the money demand and thereby liberate banks from unwanted deposits and leverage. ${ }^{63}$

\footnotetext{
${ }^{62}$ See "SVB's collapse is not a harbinger of another 2008" by Robert Armstrong, Financial Times, March 11, 2023.

${ }^{63}$ The monetary service of government liabilities is an old theme (Patinkin, 1965; Friedman, 1969). Recent contributions include Bansal and Coleman (1996), Bansal, Coleman, and Lundblad (2011), Krishnamurthy and VissingJørgensen (2012), Greenwood, Hanson, and Stein (2015), Bolton and Huang (2016), and Nagel (2016).
} 


\section{References}

Acharya, V. V. and N. Mora (2015). A crisis of banks as liquidity providers. The Journal of Finance $70(1), 1-43$.

Admati, A. and M. Hellwig (2013). The Bankers' New Clothes: What's Wrong with Banking and What to Do about It. Princeton, NJ: Princeton University Press.

Adrian, T., N. Boyarchenko, and H. S. Shin (2015). The cyclicality of leverage. Staff Reports 442, Federal Reserve Bank of New York.

Afonso, G. and H. S. Shin (2011). Precautionary demand and liquidity in payment systems. Journal of Money, Credit and Banking 43(s2), 589-619.

Allen, F., E. Carletti, and R. Marquez (2015). Deposits and bank capital structure. Journal of Financial Economics 118(3), 601 - 619. NBER Symposium on New perspectives on corporate capital structures.

Allen, F. and D. Gale (2004). Financial intermediaries and markets. Econometrica 72(4), 10231061.

Ashcraft, A., J. McAndrews, and D. Skeie (2011). Precautionary reserves and the interbank market. Journal of Money, Credit and Banking 43(s2), 311-348.

Asquith, P. and D. W. Mullins (1986). Signalling with dividends, stock repurchases, and equity issues. Financial Management 15(3), 27-44.

Atkeson, A. G., A. d'Avernas, A. L. Eisfeldt, and P.-O. Weill (2019). Government guarantees and the valuation of american banks. NBER Macroeconomics Annual 33, 81-145.

Bansal, R. and W. J. Coleman (1996). A monetary explanation of the equity premium, term premium, and risk-free rate puzzles. Journal of Political Economy 104(6), 1135-1171.

Bansal, R., W. J. Coleman, and C. T. Lundblad (2011). Endogenous liquidity supply. 2011 Meeting Papers 1200, Society for Economic Dynamics.

Baron, M. (2020). Countercyclical Bank Equity Issuance. The Review of Financial Studies 33(9), 4186-4230.

Baron, M., E. Verner, and W. Xiong (2020, 10). Banking Crises Without Panics. The Quarterly Journal of Economics 136(1), 51-113.

Basel Committee on Banking Supervision (2013). Basel III: The Liquidity Coverage Ratio and liquidity risk monitoring tools. Technical report, Bank for International Settlements. 
Baumol, W. J. (1952). The transactions demand for cash: An inventory theoretic approach. The Quarterly Journal of Economics 66(4), 545-556.

Bech, M. L. and R. Garratt (2003). The intraday liquidity management game. Journal of Economic Theory 109(2), 198 - 219. Festschrift for Karl Shell.

Begenau, J. (2020). Capital requirements, risk choice, and liquidity provision in a business-cycle model. Journal of Financial Economics 136(2), 355-378.

Begenau, J., S. Bigio, J. Majerovitz, and M. Vieyra (2019). Banks adjust slowly: Evidence and lessons for modeling. Working paper, Bank of Canada, MIT, Stanford, and UCLA.

Begenau, J. and T. Landvoigt (2018). Financial regulation in a quantitative model of the modern banking system. Working paper, Stanford University and Wharton School of the University of Pennsylvania.

Begenau, J., M. Piazzesi, and M. Schneider (2015). Banks' risk exposures. Working paper, Stanford University.

Begenau, J. and E. Stafford (2021). Stable NIM and interest rate exposure of us banks. Working paper, Stanford University.

Ben-David, I., A. Palvia, and C. Spatt (2017). Banks' internal capital markets and deposit rates. Journal of Financial and Quantitative Analysis 52(5), 1797-1826.

Ben-David, I., A. A. Palvia, and R. M. Stulz (2020). How important is moral hazard for distressed banks? Dice center working paper,, The Ohio State University Fisher College of Business.

Berlin, M. and L. J. Mester (1999). Deposits and Relationship Lending. The Review of Financial Studies 12(3), 579-607.

Bhattacharya, S. and D. Gale (1987). Preference shocks, liquidity, and central bank policy. In W. Barnett and K. Singleton (Eds.), New approaches to monetary economics. Cambridge, UK: Cambridge University Press.

Biais, B., T. Mariotti, G. Plantin, and J.-C. Rochet (2007). Dynamic security design: Convergence to continuous time and asset pricing implications. The Review of Economic Studies 74(2), 345390.

Bianchi, J. and S. Bigio (2014). Banks, liquidity management and monetary policy. Working Paper Series 20490, National Bureau of Economic Research.

Bigio, S. and Y. Sannikov (2019). A model of intermediation, money, interest, and prices. Working paper, Stanford and UCLA. 
Black, L., I. Floros, and R. Sengupta (2016). Raising capital when the going gets tough: U.S. bank equity issuance from 2001 to 2014. Working paper RWP 16-05, Federal Reserve Bank of Kansas City.

Bolton, P., H. Chen, and N. Wang (2011). A unified theory of Tobin's q, corporate investment, financing, and risk management. The Journal of Finance 66(5), 1545-1578.

Bolton, P. and X. Freixas (2000). Equity, bonds, and bank debt: Capital structure and financial market equilibrium under asymmetric information. Journal of Political Economy 108(2), 324351.

Bolton, P. and H. Huang (2016). The capital structure of nations. Working paper, Columbia University.

Bolton, P. and F. Samama (2014, 08). Capital access bonds: contingent capital with an option to convert. Economic Policy 27(70), 275-317.

Bolton, P., T. Santos, and J. A. Scheinkman (2018). Savings gluts and financial fragility. Working paper, Columbia University.

Boot, A. W. A. and A. V. Thakor (2000). Can relationship banking survive competition? The Journal of Finance 55(2), 679-713.

Boyson, N. M., R. Fahlenbrach, and R. M. Stulz (2016). Why Don't All Banks Practice Regulatory Arbitrage? Evidence from Usage of Trust-Preferred Securities. The Review of Financial Studies 29(7), 1821-1859.

Brunnermeier, M. K., J. Abadi, and Y. Koby (2023). The reversal interest rate. American Economic Review forthcoming.

Brunnermeier, M. K., S. Merkel, and Y. Sannikov (2020). Debt as safe asset: Mining the bubble. Working paper, Princeton University and Stanford University.

Brunnermeier, M. K. and Y. Sannikov (2014). A macroeconomic model with a financial sector. American Economic Review 104(2), 379-421.

Brunnermeier, M. K. and Y. Sannikov (2016). The I theory of money. Working paper, Princeton University.

Caballero, R. J., E. Farhi, and P. Gourinchas (2008). An equilibrium model of "global imbalances" and low interest rates. American Economic Review 98(1), 358-93.

Calomiris, C. W. and C. M. Kahn (1991). The role of demandable debt in structuring optimal banking arrangements. The American Economic Review 81(3), 497-513. 
Carletti, E., I. Goldstein, and A. Leonello (2019). The interdependence of bank capital and liquidity. BAFFI CAREFIN Working Papers 19128, BAFFI CAREFIN, Centre for Applied Research on International Markets Banking Finance and Regulation, Universita' Bocconi, Milano, Italy.

Choudhary, M. A. and N. Limodio (2017). Deposit Volatility, Liquidity and Long-Term Investment: Evidence from a Natural Experiment in Pakistan. Working Papers 613, IGIER (Innocenzo Gasparini Institute for Economic Research), Bocconi University.

Copeland, A., D. Duffie, and Y. Yang (2021). Reserves were not so ample after all. Staff Reports 974, Federal Reserve Bank of New York.

Davydiuk, T. (2017). Dynamic bank capital requirements. Working paper, Carnegie Mellon University David A. Tepper School of Business.

De Nicolò, G., A. Gamba, and M. Lucchetta (2014). Microprudential Regulation in a Dynamic Model of Banking. The Review of Financial Studies 27(7), 2097-2138.

DeAngelo, H., L. DeAngelo, and T. M. Whited (2011). Capital structure dynamics and transitory debt. Journal of Financial Economics 99(2), 235-261.

DeAngelo, H. and R. M. Stulz (2015). Liquid-claim production, risk management, and bank capital structure: Why high leverage is optimal for banks. Journal of Financial Economics 116(2), 219 $-236$.

Décamps, J.-P., S. Gryglewicz, E. Morellec, and S. Villeneuve (2017). Corporate Policies with Permanent and Transitory Shocks. The Review of Financial Studies 30(1), 162-210.

Décamps, J.-P., T. Mariotti, J.-C. Rochet, and S. Villeneuve (2011). Free cash flow, issuance costs, and stock prices. The Journal of Finance 66(5), 1501-1544.

DeMarzo, P. M. and M. J. Fishman (2007). Optimal Long-Term Financial Contracting. The Review of Financial Studies 20(6), 2079-2128.

DeMarzo, P. M. and Z. He (2021). Leverage dynamics without commitment. The Journal of Finance 76(3), 1195-1250.

DeMarzo, P. M. and Y. Sannikov (2006). Optimal security design and dynamic capital structure in a continuous-time agency model. The Journal of Finance 61(6), 2681-2724.

Denbee, E., C. Julliard, Y. Li, and K. Yuan (2018). Network risk and key players: A structural analysis of interbank liquidity. Working paper, Bank of England, London School of Economics, and the Ohio State University. 
Diamond, D. and A. Kashyap (2016). Chapter 29 - liquidity requirements, liquidity choice, and financial stability. Volume 2 of Handbook of Macroeconomics, pp. 2263-2303. Elsevier.

Diamond, D. W. (1984). Financial intermediation and delegated monitoring. The Review of Economic Studies 51(3), 393-414.

Diamond, D. W. and P. H. Dybvig (1983). Bank runs, deposit insurance, and liquidity. Journal of Political Economy 91(3), 401-419.

Diamond, D. W. and Z. He (2014). A theory of debt maturity: The long and short of debt overhang. The Journal of Finance 69(2), 719-762.

Donaldson, J. R., G. Piacentino, and A. Thakor (2018). Warehouse banking. Journal of Financial Economics 129(2), $250-267$.

Drechsler, I., A. Savov, and P. Schnabl (2017). The deposits channel of monetary policy. Quarterly Journal of Economics 132(4), 1819-1876.

Drechsler, I., A. Savov, and P. Schnabl (2018). A model of monetary policy and risk premia. The Journal of Finance 73(1), 317-373.

Drechsler, I., A. Savov, and P. Schnabl (2021). Banking on deposits: Maturity transformation without interest rate risk. The Journal of Finance 76(3), 1091-1143.

Duffie, D. (2001). Dynamic Asset Pricing Theory. Princeton, NJ: Princeton University Press.

Dumas, B. (1991). Super contact and related optimality conditions. Journal of Economic Dynamics and Control 15(4), 675-685.

Eckbo, B. E., R. W. Masulis, and O. Norli (2007). Chapter 6 - security offerings. In B. E. Eckbo (Ed.), Handbook of Corporate Finance: Empirical Corporate Finance, Volume 1 of Handbook of Finance Series, pp. 233-373. Elsevier/North-Holland.

English, W. B., S. J. Van den Heuvel, and E. Zakrajšek (2018). Interest rate risk and bank equity valuations. Journal of Monetary Economics 98(C), 80-97.

Freixas, X., B. M. Parigi, and J.-C. Rochet (2000). Systemic risk, interbank relations, and liquidity provision by the central bank. Journal of Money, Credit and Banking 32(3), 611-638.

Friedman, M. (1969). The Optimum Quantity of Money and Other Essays. Chicago, I.L.: Aldine Aldine Transaction.

Furfine, C. H. (2000). Interbank payments and the daily federal funds rate. Journal of Monetary Economics 46(2), 535 - 553. 
Gatev, E. and P. E. Strahan (2006). Banks' advantage in hedging liquidity risk: Theory and evidence from the commercial paper market. The Journal of Finance 61(2), 867-892.

Gersbach, H. and J.-C. Rochet (2017). Capital regulation and credit fluctuations. Journal of Monetary Economics 90, 113 - 124.

Gertler, M. and N. Kiyotaki (2010). Chapter 11 - Financial intermediation and credit policy in business cycle analysis. In B. M. Friedman and M. Woodford (Eds.), Handbook of Monetary Economics, Volume 3 of Handbook of Monetary Economics, pp. 547 - 599. Elsevier.

Glasserman, P. and B. Nouri (2016). Market-triggered changes in capital structure: Equilibrium price dynamics. Econometrica 84(6), 2113-2153.

Goldstein, I. and A. Pauzner (2005). Demand-deposit contracts and the probability of bank runs. The Journal of Finance 60(3), 1293-1327.

Gomes, J. a. F. (2001, December). Financing investment. American Economic Review 91(5), $1263-1285$.

Gorton, G. B. and G. G. Pennacchi (1995). Banks and loan sales marketing nonmarketable assets. Journal of Monetary Economics 35(3), 389 - 411.

Gourinchas, P. and H. Rey (2016). Real interest rates, imbalances and the curse of regional safe asset providers at the zero lower bound. Working Paper 22618, National Bureau of Economic Research.

Greenwood, R., S. G. Hanson, and J. C. Stein (2015). A comparative-advantage approach to government debt maturity. The Journal of Finance 70(4), 1683-1722.

Gropp, R. and F. Heider (2010). The Determinants of Bank Capital Structure*. Review of Finance 14(4), 587-622.

Hannan, T. H. and R. M. Adams (2011). Consumer switching costs and firm pricing: Evidence from bank pricing of deposit accounts. The Journal of Industrial Economics 59(2), 296-320.

Hanson, S., A. Shleifer, J. C. Stein, and R. W. Vishny (2015). Banks as patient fixed-income investors. Journal of Financial Economics 117(3), 449-469.

Hayashi, F. (1982). Tobin's marginal q and average q: A neoclassical interpretation. Econometrica 50(1), 213-224.

He, Z. and A. Krishnamurthy (2012). A model of capital and crises. The Review of Economic Studies 79(2), 735-777. 
He, Z. and A. Krishnamurthy (2013). Intermediary asset pricing. American Economic Review 103(2), 732-70.

He, Z., A. Krishnamurthy, and K. Milbradt (2019). A model of safe asset determination. American Economic Review 109(4), 1230-62.

He, Z. and A. Manela (2016). Information acquisition in rumor-based bank runs. The Journal of Finance 71(3), 1113-1158.

He, Z. and K. Milbradt (2016). Dynamic debt maturity. The Review of Financial Studies 29(10), $2677-2736$.

He, Z., S. Nagel, and Z. Song (2021). Treasury inconvenience yields during the covid-19 crisis. Journal of Financial Economics.

He, Z. and W. Xiong (2012, 02). Dynamic Debt Runs. The Review of Financial Studies 25(6), $1799-1843$.

Heider, F., F. Saidi, and G. Schepens $(2019,02)$. Life below Zero: Bank Lending under Negative Policy Rates. The Review of Financial Studies 32(10), 3728-3761.

Holmström, B. and J. Tirole (1997). Financial intermediation, loanable funds, and the real sector. The Quarterly Journal of Economics 112(3), 663-691.

Hugonnier, J., S. Malamud, and E. Morellec (2015). Capital supply uncertainty, cash holdings, and investment. Review of Financial Studies 28(2), 391-445.

Hugonnier, J. and E. Morellec (2017). Bank capital, liquid reserves, and insolvency risk. Journal of Financial Economics 125(2), 266-285.

Jermann, U. and H. Xiang (2021). Dynamic banking with non-maturing deposits. Working paper, Peking University and University of Pennsylvania.

Kargar, M., J. Passadore, and D. Silva (2020). A competitive search theory of asset pricing. Working paper, Einaudi Institute for Economics and Finance and University of Illinois at UrbanaChampaign.

Kashyap, A. K., R. Rajan, and J. C. Stein (2002). Banks as liquidity providers: An explanation for the coexistence of lending and deposit-taking. The Journal of Finance 57(1), 33-73.

Kim, M., D. Kliger, and B. Vale (2003). Estimating switching costs: the case of banking. Journal of Financial Intermediation 12(1), 25-56.

Kiser, E. K. (2002). Predicting household switching behavior and switching costs at depository institutions. Review of Industrial Organization 20(4), 349-365. 
Klimenko, N., S. Pfeil, J.-C. Rochet, and G. D. Nicolo (2016). Aggregate bank capital and credit dynamics. Swiss Finance Institute Research Paper Series 16-42.

Krishnamurthy, A. (2002). The bond/old-bond spread. Journal of Financial Economics 66(2), 463 - 506. Limits on Arbitrage.

Krishnamurthy, A. and A. Vissing-Jørgensen (2012). The aggregate demand for treasury debt. Journal of Political Economy 120(2), 233-267.

Krishnamurthy, A. and A. Vissing-Jørgensen (2015). The impact of Treasury supply on financial sector lending and stability. Journal of Financial Economics 118(3), 571-600.

Lee, I., S. Lochhead, J. Ritter, and Q. Zhao (1996). The costs of raising capital. Journal of Financial Research 19(1), 59-74.

Leland, H. (1994a). Bond prices, yield spreads, and optimal capital structure with default risk. Research Program in Finance Working Papers RPF-240, University of California at Berkeley.

Leland, H. E. (1994b). Corporate debt value, bond covenants, and optimal capital structure. The Journal of Finance 49(4), 1213-1252.

Leland, H. E. (1998). Agency costs, risk management, and capital structure. The Journal of Finance 53(4), 1213-1243.

Li, Y. (2019). Government debt and bank leverage cycle: An analysis of public and intermediated liquidity. Dice center working paper,, The Ohio State University Fisher College of Business.

Li, Y. and Y. Li (2021). Payment risk and bank lending. Working paper, University of Washington and Federal Reserve Board.

Lin, L. (2019, 07). Bank Deposits and the Stock Market. The Review of Financial Studies 33(6), 2622-2658.

Lucas, D. J. and R. L. McDonald (1990). Equity issues and stock price dynamics. The Journal of Finance 45(4), 1019-1043.

Lucas, R. E. and E. C. Prescott (1971). Investment under uncertainty. Econometrica 39(5), 659681.

Lucas, R. E. J. and J. P. Nicolini (2015). On the stability of money demand. Journal of Monetary Economics 73, $48-65$.

Maggiori, M. (2017). Financial intermediation, international risk sharing, and reserve currencies. American Economic Review 107(10), 3038-71. 
Mehran, H. and A. Thakor (2011, 04). Bank Capital and Value in the Cross-Section. The Review of Financial Studies 24(4), 1019-1067.

Merton, R. C. (1969). Lifetime portfolio selection under uncertainty: The continuous-time case. The Review of Economics and Statistics 51(3), 247-257.

Minton, B. A., R. M. Stulz, and A. G. Taboada (2019). Are the Largest Banks Valued More Highly? The Review of Financial Studies 32(12), 4604-4652.

Moreira, A. and A. Savov (2017). The macroeconomics of shadow banking. The Journal of Finance 72(6), 2381-2432.

Myers, S. C. and N. S. Majluf (1984). Corporate financing and investment decisions when firms have information that investors do not have. Journal of Financial Economics 13(2), 187 - 221.

Nagel, S. (2016, 07). The Liquidity Premium of Near-Money Assets*. The Quarterly Journal of Economics 131(4), 1927-1971.

Nguyen, T. T. (2015). Bank capital requirements: A quantitative analysis. Charles A. Dice Center working paper 2015-03-14, The Ohio State University Fisher College of Business.

Parlour, C. A., U. Rajan, and J. Walden (2020). Payment system externalities and the role of central bank digital currency. Journal of Finance forthcoming.

Parlour, C. A., R. Stanton, and J. Walden (2012). Financial flexibility, bank capital flows, and asset prices. The Journal of Finance 67(5), 1685-1722.

Patinkin, D. (1965). Money, Interest, and Prices: An Integration of Monetary and Value Theory (2 ed.). New York, N.Y.: Harper \& Row.

Pennacchi, G. (2010). A structural model of contingent bank capital. Working Papers (Old Series) 1004, Federal Reserve Bank of Cleveland.

Pennacchi, G. and A. Tchistyi (2018). Contingent Convertibles with Stock Price Triggers: The Case of Perpetuities. The Review of Financial Studies 32(6), 2302-2340.

Pennacchi, G. and A. Tchistyi (2019). On equilibrium when contingent capital has a market trigger: A correction to Sundaresan and Wang Journal of Finance (2015). The Journal of Finance 74(3), 1559-1576.

Pennacchi, G. G. (1988). Loan sales and the cost of bank capital. The Journal of Finance 43(2), 375-396.

Phelan, G. (2016). Financial intermediation, leverage, and macroeconomic instability. American Economic Journal: Macroeconomics 8(4), 199-224. 
Piazzesi, M. and M. Schneider (2016). Payments, credit and asset prices. Working paper, Stanford University.

Plosser, M. C. and J. A. Santos (2014). Banks' incentives and the quality of internal risk models. Staff Reports 704, Federal Reserve Bank of New York.

Ramakrishnan, R. T. S. and A. V. Thakor (1984). Information reliability and a theory of financial intermediation. The Review of Economic Studies 51(3), 415-432.

Rampini, A. A. and S. Viswanathan (2018). Financial Intermediary Capital. The Review of Economic Studies 86(1), 413-455.

Repullo, R. (2020). The reversal interest rate: A critical review. Working Paper DP15367, Centre for Economic Policy Research.

Repullo, R. and J. Suarez (2012). The Procyclical Effects of Bank Capital Regulation. The Review of Financial Studies 26(2), 452-490.

Riddick, L. A. and T. M. Whited (2009). The corporate propensity to save. The Journal of Finance 64(4), 1729-1766.

Rognlie, M. (2016). What lower bound? Monetary policy with negative interest rates. Working paper, Northwestern University.

Sharpe, S. A. (1997). The effect of consumer switching costs on prices: A theory and its application to the bank deposit market. Review of Industrial Organization 12(1), 79-94.

Stein, J. C. (2012). Monetary policy as financial stability regulation. The Quarterly Journal of Economics 127(1), 57-95.

Sundaresan, S. and Z. Wang (2014). Bank liability structure. Working paper, Columbia University and Indiana University.

Thakor, A. V. (2014). Bank capital and financial stability: An economic trade-off or a faustian bargain? Annual Review of Financial Economics 6(1), 185-223.

Tobin, J. (1956). The interest-elasticity of transactions demand for cash. The Review of Economics and Statistics 38(3), 241-247.

Van den Heuvel, S. J. (2018). The welfare effects of bank liquidity and capital requirements. Working paper, Federal Reserve Board.

Vandeweyer, Q. (2019). Treasury debt and the pricing of short-term assets. Working paper, European Central Bank and Sciences Po. 
Wang, O. (2018). Banks, low interest rates, and monetary policy transmission. Working paper, New York University. 


\section{A An Extended Model with Liquidity Requirement}

In this appendix, the bank must hold assets that are more liquid than loans (Drechsler, Savov, and Schnabl, 2018). These assets can be reserves or other high-quality liquid assets (HQLA). The bank chooses liquidity holdings, denoted by $R_{t}$, which earns an interest rate $\iota(<r)$. The bank may to pay a carry cost for having a more liquid asset portfolio. The law of motion of equity capital is

$$
\begin{aligned}
d K_{t}= & A_{t}\left[\left(r+\alpha_{A}\right) d t+\sigma_{A} d \mathcal{W}_{t}^{A}\right]-B_{t} r d t-X_{t} i_{t} d t-C\left(n\left(i_{t}\right), X_{t}\right) d t \\
& -d U_{t}+d F_{t}+R_{t} \iota d t-S\left(R_{t}, X_{t}, A_{t}\right) d t
\end{aligned}
$$

The last term, $S\left(R_{t}, X_{t}, A_{t}\right)$, captures loss due to illiquidity of asset portfolio. This specification is isomorphic to the following microfoundation: a Poisson-arriving withdrawal of a large amount of deposits can only be met by liquidity holdings and selling a large amount of loans in exchange for liquidity incurs a fire-sale cost (Moreira and Savov, 2017; Drechsler, Savov, and Schnabl, 2018). Accordingly, we assume $S_{R}\left(R_{t}, X_{t}, A_{t}\right)<0, S_{X}\left(R_{t}, X_{t}, A_{t}\right)>0$, and $S_{A}\left(R_{t}, X_{t}, A_{t}\right)>0$.

The bank has to meet the regulatory requirement of liquidity holdings:

$$
R_{t} \geq \xi_{R} X_{t}
$$

This constraint can be motivated by reserve requirement or more recent requirement on liquidity coverage ratio (Basel Committee on Banking Supervision, 2013). Risk-free bonds $\left(B_{t}<0\right)$ are not part of liquidity holdings. Here we draw the distinction between liquid and illiquid safe assets in line with the evidence that these assets offer different yields (Krishnamurthy, 2002; Nagel, 2016). Let $\pi_{t}^{R}$ denote the weight of $\left(X_{t}+K_{t}\right)$ on $R_{t}$. We rewrite the law of motion for $K_{t}$ in (A.1) as

$$
\begin{aligned}
d K_{t}= & \left(X_{t}+K_{t}\right)\left[r+\pi_{t}^{A} \alpha_{A}-\pi_{t}^{R}(r-\iota)\right] d t+\left(X_{t}+K_{t}\right) \pi_{t}^{A} \sigma_{A} d \mathcal{W}_{t}^{A}-X_{t} i_{t} d t \\
& -C\left(n\left(i_{t}\right), X_{t}\right) d t-S\left(\pi_{t}^{R}\left(X_{t}+K_{t}\right), X_{t}, \pi_{t}^{A}\left(X_{t}+K_{t}\right)\right)-d U_{t}+d F_{t}
\end{aligned}
$$

Accordingly, the HJB equation in the interior region where $d U_{t}=0$ and $d F_{t}=0$ is

$$
\begin{aligned}
\rho V(X, K) & =\max _{\left\{\pi^{A}, \pi^{R}, i\right\}} V_{X}(X, K) X\left[-\delta_{X}+n(i)\right]+\frac{1}{2} V_{X X}(X, K) X^{2} \sigma_{X}^{2} \\
& +V_{K}(X, K)(X+K)\left[r+\pi^{A} \alpha_{A}-\pi^{R}(r-\iota)\right]+\frac{1}{2} V_{K K}(X, K)(X+K)^{2}\left(\pi^{A} \sigma_{A}\right)^{2} \\
& -V_{K}(X, K)\left[S\left(\pi^{R}(X+K), X, \pi^{A}(X+K)\right)+X i+C(n(i), X)\right] \\
& +V_{X K}(X, K) X(X+K) \pi^{A} \sigma_{A} \sigma_{X} \phi .
\end{aligned}
$$


Risk-taking. The first-order condition for $\pi^{A}$ gives the following solution:

$$
\pi^{A}=\min \left\{\frac{\alpha_{A}+\epsilon(X, K) \sigma_{A} \sigma_{X} \phi-S_{A}(R, X, A)}{\gamma(X, K) \sigma_{A}^{2}\left(\frac{X+K}{K}\right)}, \frac{K}{\xi_{K}(X+K)}\right\} .
$$

While setting up $\pi^{A}=A /(X+K)$ as the control variable is convenient for solving the model, it is intuitive to express the solution in loan-to-capital ratio, i.e., $A / K=\pi^{A}(X+K) / K$ :

$$
\frac{A}{K}=\min \left\{\frac{\alpha_{A}+\epsilon(X, K) \sigma_{A} \sigma_{X} \phi-S_{A}(R, X, A)}{\gamma(X, K) \sigma_{A}^{2}}, \frac{1}{\xi_{K}}\right\} .
$$

In comparison with (19), the only difference is that the numerator is deducted by $S_{A}(R, X, A)$.

Liquidity Holdings. When the liquidity requirement (A.2) does not bind, the optimality condition for $\pi^{R}$ equates the marginal cost of holding reserves, i.e., accepting the below- $r$ rate of return $\iota$, and the marginal benefit of holding reserves to reduce the payment settlement cost:

$$
r-\iota=-S_{R}\left(\pi^{R}(X+K), X, \pi^{A}(X+K)\right) .
$$

The reserve requirement can be rewritten as the following restriction on $\pi^{R}$ :

$$
\pi^{R} \geq \frac{\xi_{R} X}{(X+K)}
$$

Next, we specify the functional form of $S(R, X, A)$ that satisfies the properties that $S(R, X, A)$ decreases in $R$ and increases in $X$ and $A$ :

$$
S(R, X, A)=\frac{1}{2} \frac{\left(\chi_{1} X+\chi_{2} A\right)^{2}}{R} .
$$

The numerator is convex in $X$ and $A$ while the denominator is linear in $R$. Therefore, to maintain the same level of $S(R, X, A)$, the bank will have to hold increasingly more liquidity as it expands its balance sheet (i.e., increases $X$ and $A$ ). This captures the decreasing marginal return to liquidity holdings that have been microfounded in various ways (Moreira and Savov, 2017).

Under this functional form of $S(R, X, A)$, we obtain

$$
S_{R}(R, X, A)=-\frac{1}{2}\left(\frac{\chi_{1} X+\chi_{2} A}{R}\right)^{2} .
$$

Therefore, the optimality condition for $\pi_{t}^{R}$ implies that $r-\iota=\frac{1}{2}\left(\frac{\chi_{1} X+\chi_{2} A}{R}\right)^{2}$, so rearranging the 
equation we obtain the following reserve holding policy

$$
R=\frac{\chi_{1} X+\chi_{2} A}{\sqrt{2(r-\iota)}}
$$

This is in the spirit of Baumol (1952) and Tobin (1956) who show that liquidity demand is equal to the product of transaction costs (mapping to $\chi_{1}$ and $\chi_{2}$ ) and transaction needs (mapping to $X$ and $A$ ) divided by the square root of two times the carry cost.

As in the main text, the bank's value function is $v(k) X$, where

$$
k=\frac{K}{X}
$$

And, as in the main text, we simplify the expressions of the effective risk aversion in (20)

$$
\gamma(k)=\frac{-V_{K K}(X, K) K}{V_{K}(X, K)}=-\frac{v^{\prime \prime}(k) k}{v^{\prime}(k)},
$$

and the elasticity of marginal value of capital to deposits

$$
\epsilon(k)=\frac{V_{X K}(X, K) X}{V_{K}(X, K)}=-\frac{v^{\prime \prime}(k) k}{v^{\prime}(k)},
$$

which happens to be equal to $\gamma(k)$. Next, we simplify loan-to-capital ratio. First, note that from (A.11), we obtain the marginal illiquidity cost of loans:

$$
S_{A}(R, X, A)=\chi_{2}\left(\frac{\chi_{1} X+\chi_{2} A}{R}\right)=\chi_{2} \sqrt{2(r-\iota)},
$$

Using (A.15) and $\epsilon(k)=\gamma(k)$, we simplify the optimal loan-to-capital ratio:

$$
\frac{A}{K}=\min \left\{\frac{\alpha_{A}-\chi_{2} \sqrt{2(r-\iota)}}{\gamma(k) \sigma_{A}^{2}}+\frac{\sigma_{X}}{\sigma_{A}} \phi, \frac{1}{\xi_{K}}\right\},
$$

The only difference from (19) is that the numerator declines by the marginal illiquidity cost $\chi_{2} \sqrt{2(r-\iota)}$. To make lending profitable, we impose the parameter restriction: $\alpha_{A}>\chi_{2} \sqrt{2(r-\iota)}$.

Using these expressions, we can rewrite the HJB equation (A.4) as

$$
\begin{aligned}
\rho v(k)= & \max _{\pi^{A}, \pi^{R}, i}\left[v(k)-v^{\prime}(k) k\right]\left(-\delta_{X}+\omega i\right)+\frac{1}{2} v^{\prime \prime}(k) k^{2} \sigma_{X}^{2} \\
& +v^{\prime}(k)(1+k)\left[r+\pi^{A} \alpha_{A}-\pi^{R}(r-\iota)\right]-v^{\prime}(k)\left[\frac{1}{2}\left(\frac{\frac{\chi_{1}}{1+k}+\chi_{2} \pi^{A}}{\pi^{R}}\right)^{2} \pi^{R}(1+k) .\right. \\
& \left.++i+\theta_{0}+\frac{\theta_{1}}{2}(\omega i)^{2}\right]+\frac{1}{2} v^{\prime \prime}(k)(1+k)^{2}\left(\pi^{A} \sigma_{A}\right)^{2}-v^{\prime \prime}(k) k(1+k) \pi^{A} \sigma_{A} \sigma_{X} \phi .
\end{aligned}
$$


To show that (A.17) is an ODE for $v(k)$, we need to show that the control variables only depend on $k$ and the level and derivatives of $v(k)$. First, from (A.16), we obtain:

$$
\pi^{A}=\left(\frac{A}{K}\right)\left(\frac{K}{K+X}\right)=\min \left\{\frac{\alpha_{A}-\chi_{2} \sqrt{2(r-\iota)}}{\gamma(k) \sigma_{A}^{2}}+\frac{\sigma_{X}}{\sigma_{A}} \phi, \frac{1}{\xi_{K}}\right\}\left(\frac{k}{1+k}\right) .
$$

Rearranging (A.11), we can solve $\pi^{R}$ as a linear function of $\pi^{A}$ and the state variable $k$ :

$$
\pi^{R}=\frac{\chi_{2}}{\sqrt{2(r-\iota)}} \pi^{A}+\frac{\chi_{1}}{(1+k) \sqrt{2(r-\iota)}}
$$

so it also only depends on $k$ and the level and derivatives of $v(k)$. The deposit rate, still given by (24) in the main text, only depends on $V_{X}(X, K)=v(k)-v^{\prime}(k) k$ and $V_{K}(X, K)=v^{\prime}(k)$.

After substituting the optimal control variables into the HJB equation, we obtained an ordinary equation with the same boundary conditions discussed in the main text. The determination of endogenous upper bound of $k$ also follows the main text. The only difference is in the determination of endogenous lower bound of $k$, i.e., the equity issuance boundary.

Let $\underline{k}_{S}$ denote the lower bound in (14) implied by the supplementary leverage ratio (SLR) requirement. The liquidity requirement implies another lower bound $\underline{k}_{L}$. Substituting (A.19) into the reserve requirement (A.8), we have

$$
\frac{\chi_{2}}{\sqrt{2(r-\iota)}} \pi^{A}+\frac{\chi_{1}}{(1+k) \sqrt{2(r-\iota)}} \geq \frac{\xi_{R}}{(1+k)}
$$

Using (A.18) to substitute out $\pi^{A}$ and rearranging the equation, we have

$$
\min \left\{\frac{\alpha_{A}-\chi_{2} \sqrt{2(r-\iota)}}{\gamma(k) \sigma_{A}^{2}}+\frac{\sigma_{X}}{\sigma_{A}} \phi, \frac{1}{\xi_{K}}\right\} k \geq \frac{\xi_{R} \sqrt{2(r-\iota)}-\chi_{1}}{\chi_{2}}
$$

In our numeric solution, the right side increases in $k$ (as $\gamma(k)$ increases in $k$ ). Therefore, (A.21) imposes a lower bound of $k$, denoted by $\underline{k}_{L}$. Therefore, we have

$$
\underline{k}=\max \left\{0, \underline{k}_{S}, \underline{k}_{L}\right\} .
$$

To sum up, introducing the bank's needs to hold reserves or HQLA leads to three changes 
in the solution. First, the new control variable, optimal liquidity-holding policy, is given by the Baumol-Tobin style money demand (A.11). Second, in the optimal risk-taking policy (A.16), $\alpha_{A}$ is subtracted by the marginal illiquidity cost of loans. Third, the equity issuance boundary is defined by (A.22) nesting considerations of liquidation, SLR requirement, and liquidity requirement.

\section{B Jump Risk in Asset Return}

Jump risk in asset returns has been emphasized as a way to distinguish the risk-return profile of banking relative to other forms of financial intermediation (e.g., Parlour, Stanton, and Walden, 2012; Hugonnier and Morellec, 2017). We extend our model to incorporate jump risk. The time subscript $t$-denotes the pre-jump value of variables. The risky investment $A_{t-}$ evolves as follows

$$
d A_{t}=A_{t-}\left(r+\alpha_{A}\right) d t+A_{t-} \sigma_{A} d \mathcal{W}_{t}^{A}-A_{t-}\left(1-Z_{t}\right) \mathcal{J}_{t}^{A}
$$

where $\mathcal{J}_{t}^{A}$ is a time-homogeneous Poisson counting process with the arrival rate $\lambda_{A}$ and the recovery rate $Z_{t}$ is uniformly distributed between $\left(1 / \xi_{L}, 1\right]$ (which implies that the SLR requirement rules out insolvency as intended). With (2) replaced by (B.1), the law of motion of $K_{t}$ is

$$
\begin{aligned}
d K_{t}= & \left(X_{t-}+K_{t-}\right)\left[\left(r+\pi_{t-}^{A} \alpha_{A}\right) d t+\pi_{t-}^{A} \sigma_{A} d \mathcal{W}_{t}^{A}-\pi_{t-}^{A}\left(1-Z_{t}\right) \mathcal{J}_{t}^{A}\right] \\
& -X_{t-} i_{t-} d t-C\left(n\left(i_{t-}\right), X_{t-}\right) d t-d U_{t}+d F_{t}
\end{aligned}
$$

The law of motion of $X_{t}$ is the same as the baseline model (see (1)).

The value function takes the form of $v(k) X$ (time subscripts suppressed) and $v(k)$ satisfies

$$
\begin{aligned}
\rho v(k)=\max _{\pi^{A}, i} & {\left[v(k)-v^{\prime}(k) k\right]\left[-\delta_{X}+n(i)\right]+\frac{1}{2} v^{\prime \prime}(k) k^{2} \sigma_{X}^{2} } \\
& +v^{\prime}(k)(1+k)\left(r+\pi^{A} \alpha_{A}\right)+\frac{1}{2} v^{\prime \prime}(k)(1+k)^{2}\left(\pi^{A} \sigma_{A}\right)^{2} \\
& -v^{\prime}(k)[i+c(n(i))]-v^{\prime \prime}(k) k(1+k) \pi^{A} \sigma_{A} \sigma_{X} \phi+\lambda_{A} \mathbb{E}[v(\tilde{k})-v(k)],
\end{aligned}
$$

where $\tilde{k}$ denotes the post-jump value of $k$ :

$$
\tilde{k}=\frac{\widetilde{K}}{X}=\frac{K-(X+K) \pi^{A}(1-Z)}{X}=k-(1+k) \pi^{A}(1-Z)
$$


If $\tilde{k}<\underline{k}$, the bank raises external equity financing to stay in compliance with the SLR requirement:

$$
v(\tilde{k})=v(\underline{k}+m)-\psi_{0}-\left(1+\psi_{1}\right)(m+\underline{k}-\tilde{k}),
$$

where the optimal $m$ (i.e., the amount of equity raised in excess of the SLR requirement) satisfies

$$
v^{\prime}(\underline{k}+m)=1+\psi_{1} .
$$

As in the baseline model, $\underline{k}$ is equal to 0.05 under the SLR requirement $\xi_{L}=20 .{ }^{64}$

In our numerical solution, we adjust the value of $\alpha_{A}$ upward by $\lambda_{A} \mathbb{E}\left[1-Z_{t}\right]$ to compensate the decline of expected return on risky investment due to the jump risk. Therefore, what changes is the distribution of return but not the expected return. The jump risk essentially extends the left tail. When the bank chooses $\pi_{A}$, it takes into consideration the loading on the jump risk and the potential negative consequence of costly equity issuance triggered by a low realization of $Z$.

Under the extra precaution, the bank takes on more risk in a less dramatic fashion than the baseline model when $k$ increases, As shown in Panel C of Figure B.1, the ratio of risky investment to equity capital rises more smoothly with $k$. Moreover, as in the baseline model, the bank seeks a higher leverage when $k$ increases by issuing bonds (i.e., increasing $B_{t}$ ), but the jump risk incentivizes the bank to build up leverage more slowly. In Panel D of Figure B.1, the ratio of bond liabilities to deposits increases more smoothly in $k$ than the baseline solution. Finally, in Figure B.1, the curves end at a higher level of $k$ than the baseline solutions. The jump risk incentivizes the bank to set a higher payout boundary of $k$ and preserve a higher level of equity capital.

As discussed in the main text, the bank profits from risky investment and deposit-taking. The expected excess return on risky investment, $\alpha_{A}$, comes with a skewed distribution (generated by both the Brownian shock, $d \mathcal{W}_{t}^{A}$, and Poisson shock, $\left.d \mathcal{J}_{t}^{A}\right)$. In contrast, to earn the net deposit spread, the bank only loads on the Brownian shock, $d \mathcal{W}_{t}^{X}$. Therefore, deposit-taking as a source of profits becomes more important under the jump risk in asset return. Panel A of Figure B.1 shows that the deposit marginal $q$ is higher than the baseline solution, and Panel B shows that the bank is willing to pay a higher interest rate to attract deposits.

\footnotetext{
${ }^{64}$ Given $\underline{k}$, the boundary conditions (16), (15) (same as (B.6)), (17), and (18) and second-order ODE (B.3) solve the $X$-scaled value function, $v(k)$, the optimal issuance amount $m$, and the upper (dividend payout) boundary $\bar{k}$. We set $\lambda_{A}=0.05$,
} 

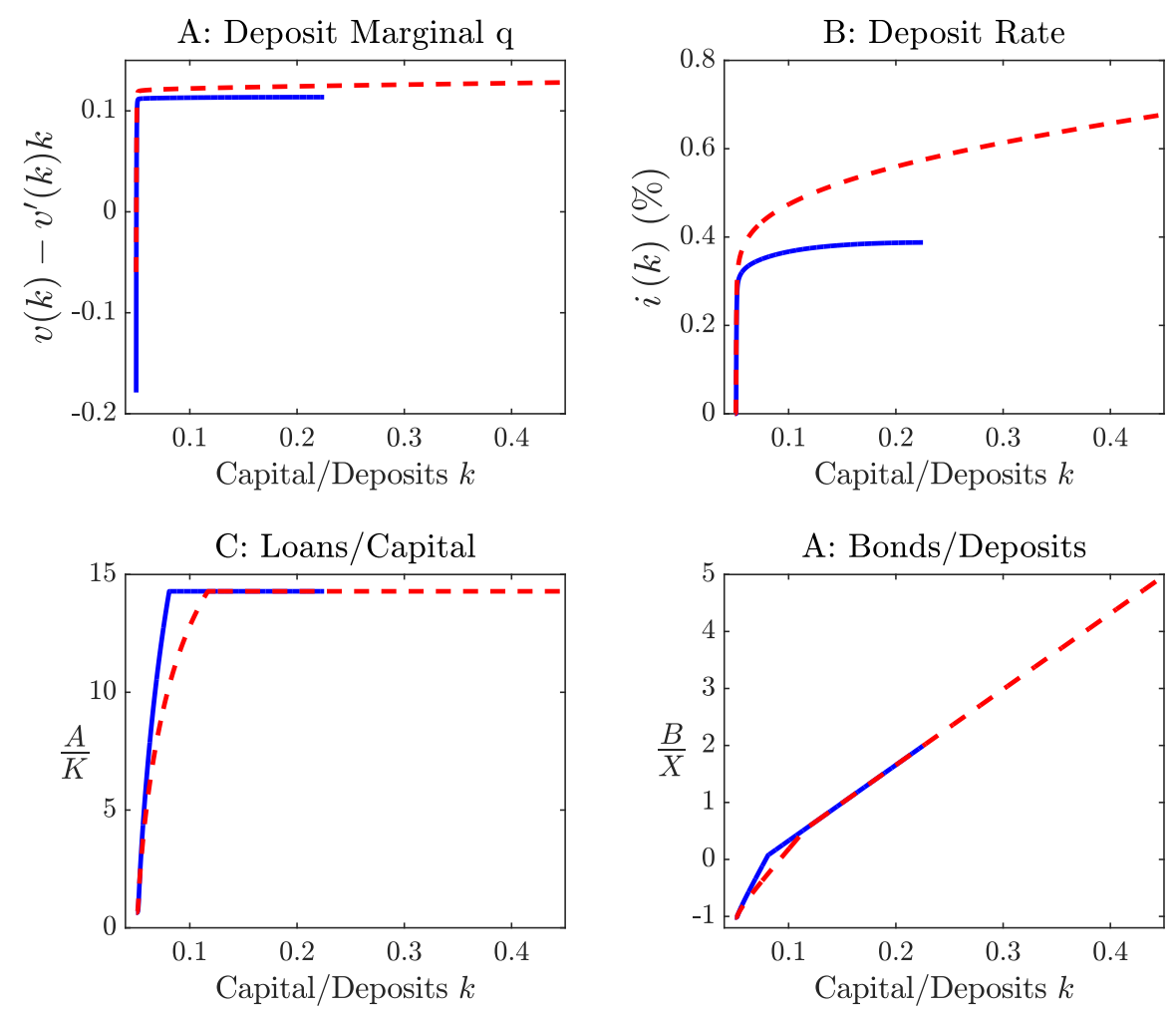

Figure B.1: The Impact of Jump Risk in Loan Returns 


\section{Solution with Negative Deposit Rate}

The unscaled HJB equation has an additional last term due to the Poisson-arriving withdrawal:

$$
\begin{aligned}
\rho V(X, K)=\max _{\left\{\pi^{A}, i\right\}} & V_{X}(X, K) X\left[-\delta_{X}+n(i)\right]+\frac{1}{2} V_{X X}(X, K) X^{2} \sigma_{X}^{2} \\
& +V_{K}(X, K)(X+K)\left(r+\pi^{A} \alpha_{A}\right)+\frac{1}{2} V_{K K}(X, K)(X+K)^{2}\left(\pi^{A} \sigma_{A}\right)^{2} \\
& -V_{K}(X, K)[X i+C(n(i), X)]+V_{X K}(X, K) X(X+K) \pi^{A} \sigma_{A} \sigma_{X} \phi \\
& +\lambda_{D}(i) \mathbb{E}^{\Delta_{X}}\left[V\left(X\left(1-\Delta_{X}\right), K-\eta_{L} \Delta_{X} X\right)-V(X, K)\right] .
\end{aligned}
$$

and the $X$-scaled HJB equation is

$$
\begin{aligned}
\rho v(k)=\max _{\pi^{A}, i} & {\left[v(k)-v^{\prime}(k) k\right]\left[-\delta_{X}+n(i)\right]+\frac{1}{2} v^{\prime \prime}(k) k^{2} \sigma_{X}^{2} } \\
& +v^{\prime}(k)(1+k)\left(r+\pi^{A} \alpha_{A}\right)+\frac{1}{2} v^{\prime \prime}(k)(1+k)^{2}\left(\pi^{A} \sigma_{A}\right)^{2} \\
& -v^{\prime}(k)[i+c(n(i))]-v^{\prime \prime}(k) k(1+k) \pi^{A} \sigma_{A} \sigma_{X} \phi \\
& +\lambda_{D}(i) \mathbb{E}^{\Delta_{X}}\left[v\left(\frac{k-\eta_{L} \Delta_{X}}{1-\Delta_{X}}\right)\left(1-\Delta_{X}\right)-v(k)\right] .
\end{aligned}
$$

The optimal choice of $\pi^{A}$ is the same as the baseline model. For the optimal choice of $i$, note that $\lambda_{D}(i)=0$ if $i>0$. The first-order condition for $i$ when $i<0$ :

$$
\begin{aligned}
\left(v(k)-v^{\prime}(k) k\right) \omega_{1}= & v^{\prime}(k)\left[1+c^{\prime}(n(i)) n^{\prime}(i)\right] \\
& +\lambda_{D}^{\prime}(i)\left\{v(k)-\mathbb{E}^{\Delta_{X}}\left[v\left(\frac{k-\eta_{L} \Delta_{X}}{1-\Delta_{X}}\right)\left(1-\Delta_{X}\right)\right]\right\} .
\end{aligned}
$$

The boundary conditions are the same as the baseline model. ${ }^{65}$

\footnotetext{
${ }^{65}$ If the Poisson shock brings $k$ below $\underline{k}$, equity issuance can happen and the bank has to pay the issuance costs. Note that the negative impact of equity issuance is already incorporated in the value function. Because if $\frac{k-\eta_{L} \Delta_{X}}{1-\Delta_{X}}<\underline{k}$, the value function takes the post-issuance value minus the issuance costs (just as described in the boundary condition).
} 


\section{Additional Results}

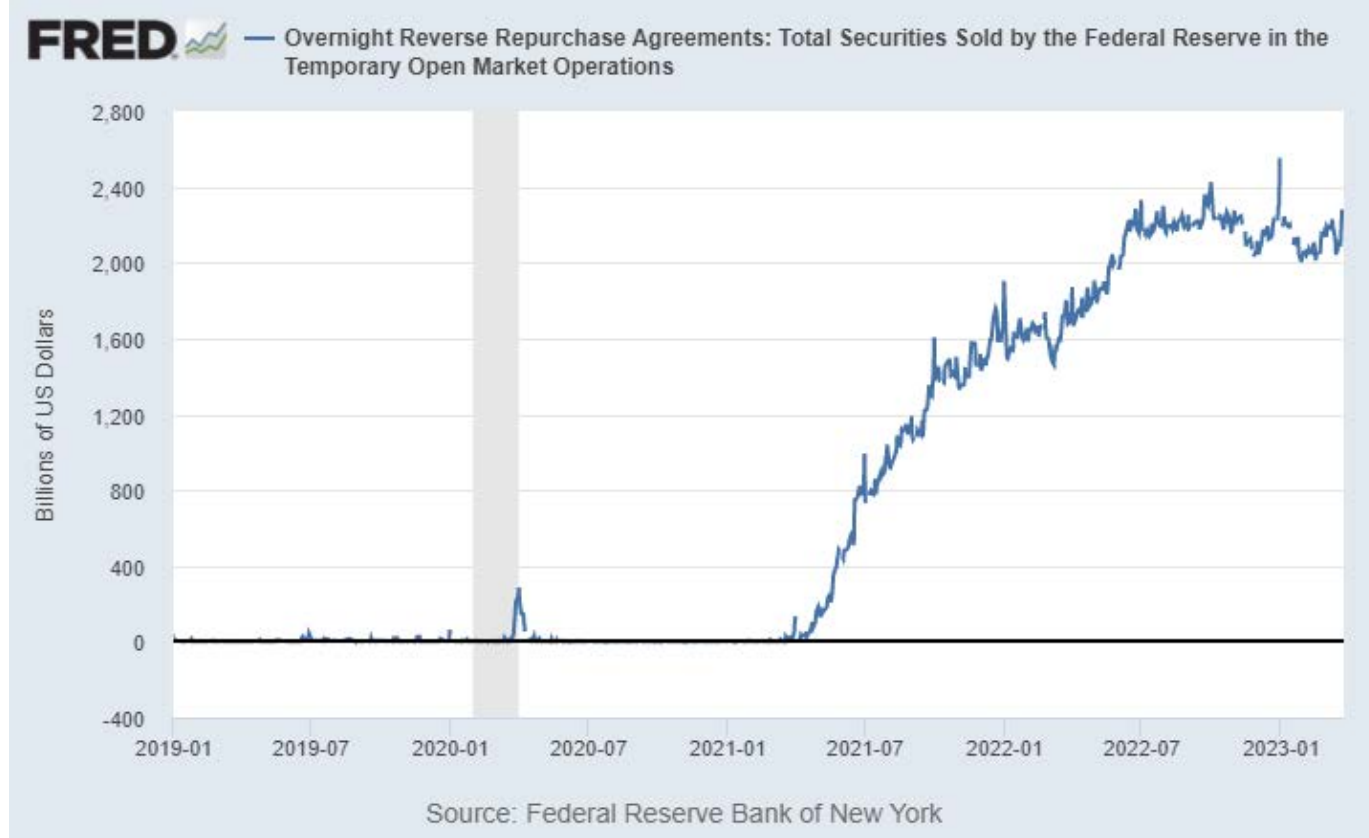

Figure D.1: Outstanding Amount of Reverse Repurchase Agreements. 

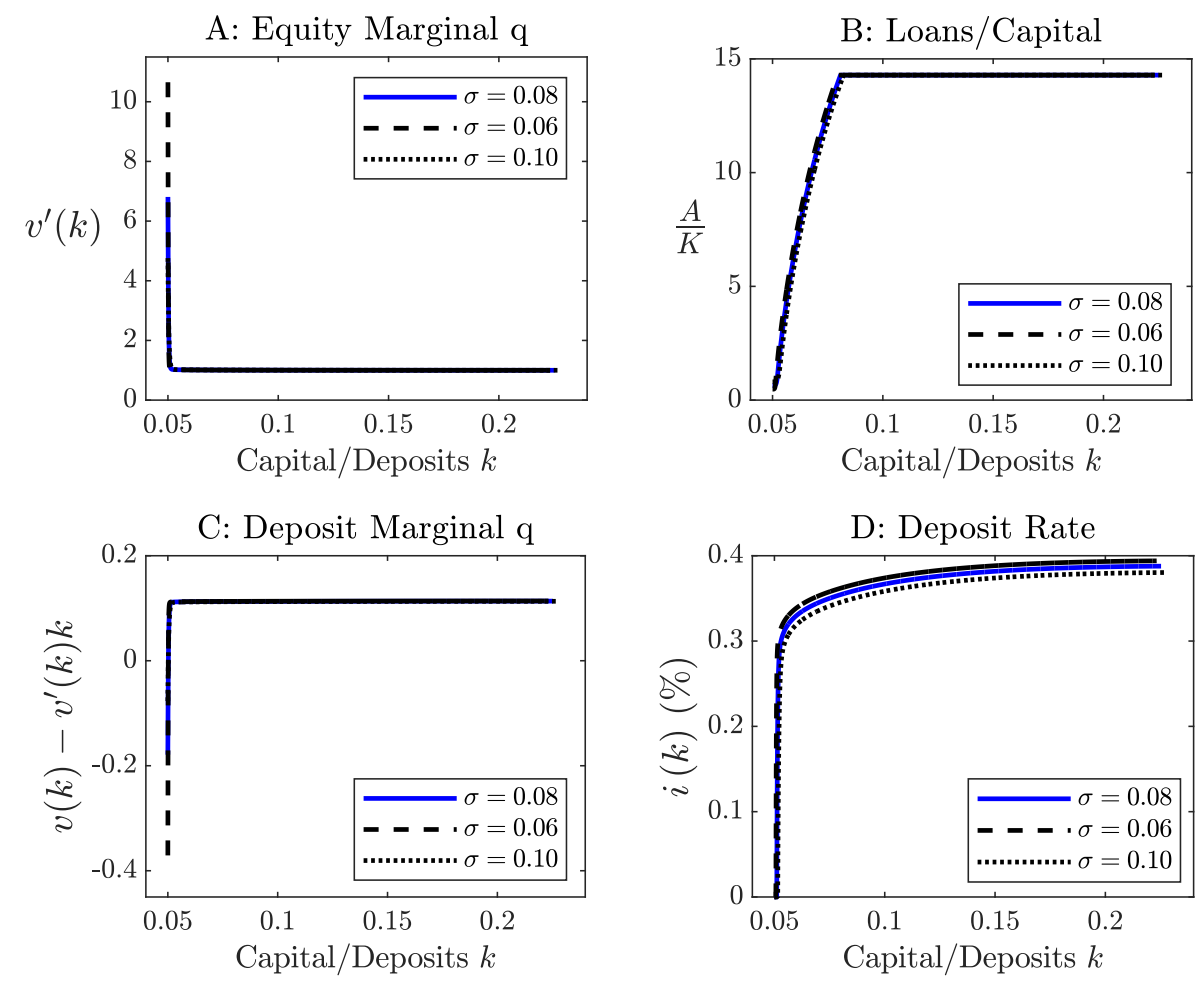

Figure D.2: Comparative Statics: Deposit-Flow Volatility $\sigma$. 

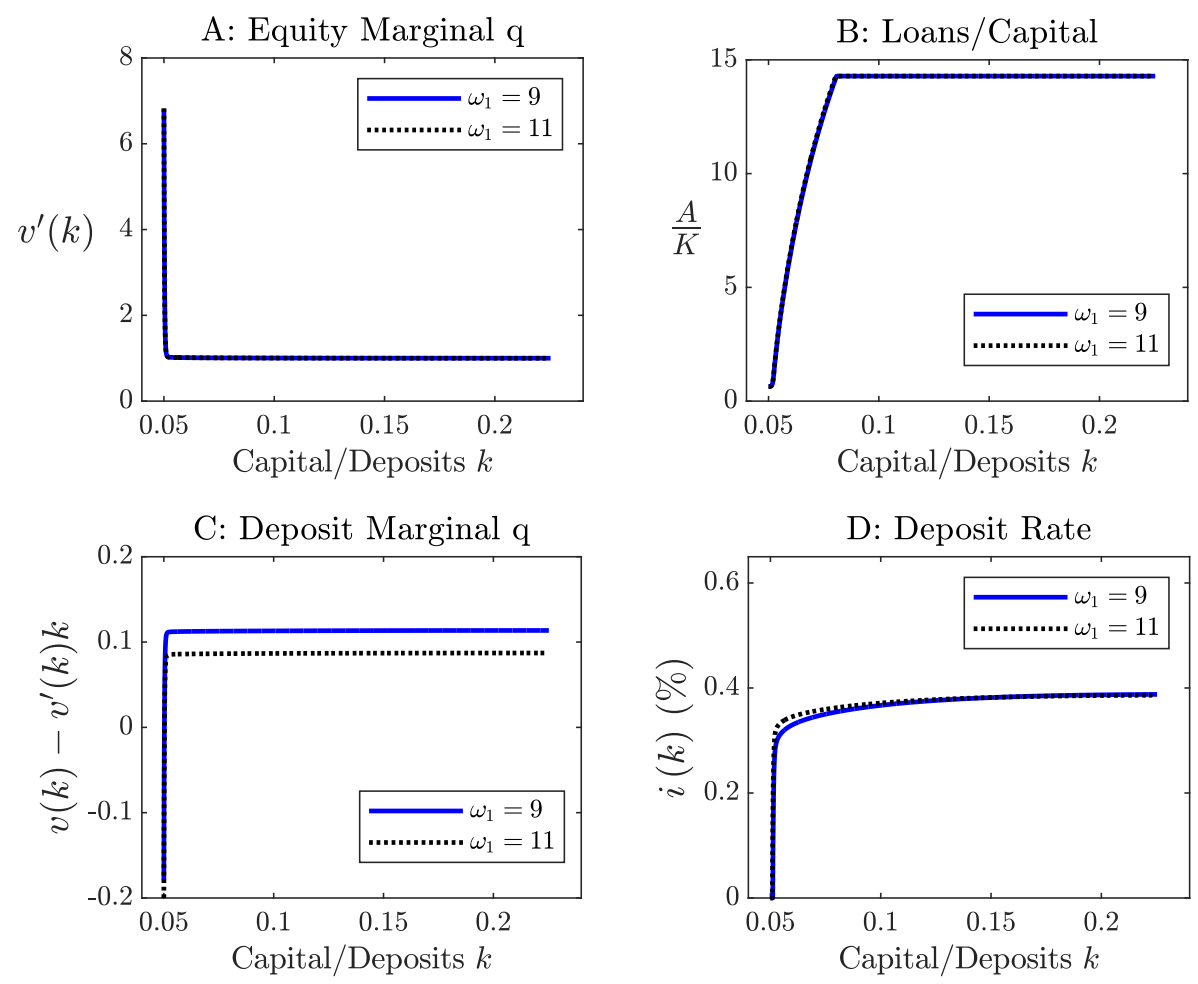

Figure D.3: Comparative Statics: Interest Rate Sensitivity of Deposit Flow. 